\title{
Computationally Driven Structure Optimization, Synthesis, and Biological Evaluation of Imidazole-based Proprotein Convertase Subtilisin/Kexin-9 (PCSK9) Inhibitors
}

\author{
Carmen Lammi, ${ }^{a}$ Jacopo Sgrignani, ${ }^{b}$ Anna Arnoldi, ${ }^{a}$ Giordano Lesma,${ }^{c}$ Claudia Spatti, ${ }^{c}$ Alessandra \\ Silvani, *,c Giovanni Grazioso ${ }^{*, a}$ \\ a Dipartimento di Scienze Farmaceutiche, Università degli Studi di Milano, Via L. Mangiagalli 25, 20133 Milan, \\ ${ }^{\mathrm{b}}$ Istituto di Ricerca in Biomedicina (IRB), Università della Svizzera Italiana (USI), Via V. Vela 6, CH-6500, \\ Bellinzona, Switzerland. \\ c Dipartimento di Chimica, Università degli Studi di Milano, Via Golgi 19, 20133 Milan, Italy.
} Italy.

\begin{abstract}
Proprotein convertase subtilisin/kexin 9 (PCSK9) is responsible for the degradation of the hepatic lowdensity lipoprotein receptor (LDLR), which in turn regulates the circulating low-density lipoprotein cholesterol (LDL-C) level. For this reason, the PCSK9 inhibition, by small molecules or peptides, is a validated therapeutic approach for fighting hypercholesterolemia and cardiovascular diseases. In this field, we have recently reported on an imidazole-based peptidomimetic that has shown PCSK9 inhibitory activity in the micromolar range. Here, by applying advanced computational techniques, the binding mechanism of that imidazole peptidomimetic was predicted. Then, among a small set of poly-imidazole analogs, compounds showing the highest theoretical affinity were suitably synthesized, relying on a vanLeusen reaction-based multicomponent strategy. One compound (named RIm13) displayed a PCSK9 inhibitory activity 10-fold lower than the template compound and, remarkably, at the concentration of 1 $\mu \mathrm{M}$, it successfully prevented the LDLR degradation mediated by PCSK9 on HepG2 cells. As well as increasing the LDL uptake at the same concentration, RIm13 represents currently one of the most potent small molecules targeting the PCSK9/LDLR PPI.
\end{abstract}




\section{INTRODUCTION}

Low-density lipoprotein receptors (LDLRs) are the major intracellular carriers of cholesterol in the blood. The LDLR is particularly abundant in the liver, the primary organ responsible for removing excess cholesterol from the body. Thus, the amount of LDLRs on the surface of liver cells determines how quickly LDL-cholesterol (LDL-C) is removed from the bloodstream. The accumulation of LDL-C in the plasma is known to cause the formation of the atherosclerotic plaque, a key risk factor of cardiovascular disease (CVD). ${ }^{1,2}$ The LDLR activity on the cell surface is mainly regulated by Proprotein Convertase Subtilisin/Kexin 9 (PCSK9), ${ }^{3,4}$ which plays an important role in regulating the degradation of hepatic LDLR $^{5-7}$ For this reason, PCSK9 is a validated therapeutic target for hypercholesterolemia treatment and CVD prevention. In this context, the main strategic approach consists of the use of specific monoclonal antibodies (mAbs), such as evolocumab and alirocumab, which function by impairing the PCSK9-LDLR protein-protein interaction (PPI). The results of the Fourier trial ${ }^{8}$ have shown that the addition of evolocumab to statin therapy over several years has significantly reduced cardiovascular morbidity and mortality in patients with evident atherosclerotic CVD. It is, however, important to underline that mAbs certainly represent a successful therapeutic strategy for inhibiting PCSK9 but are extremely expensive.

Regardless, the PCSK9-LDLR PPI remains a validated target for new drug discovery, and many efforts are currently underway to develop peptidomimetics or other small molecules capable of impairing this PPI. Since the PCSK9/LDLR X-ray crystal structure ${ }^{9}$ clearly evidences that this PPI is mediated by a $\beta$ sheet, we have recently synthesized an $N$-methyl tetra-imidazole derivative (1, MeIm, Figure 1), a minimalist peptidomimetic capable of resembling a $\beta$-strand motif. ${ }^{10,11}$ Interestingly, biological investigations have suggested that MeIm prevents PCSK9 from binding to LDLR in a dose-response manner, with an $\mathrm{IC}_{50}$ value of $11.2 \mu \mathrm{M}$. Moreover, MeIm improves the functional ability of human hepatic HepG2 cells to uptake LDL from the extracellular environment, with an $\mathrm{EC}_{50}$ equal to $6.0 \mu \mathrm{M}$. The literature has reported on the use of the Exploring Key Orientations (EKO) procedure, as well as one round of combinatorial fragment-based virtual docking, to discover compounds capable of impairing the PCSK9/LDLR PPI. Three hit compounds bound PCSK9 with $\mathrm{IC}_{50}$ values in the 20-40 $\mu \mathrm{M}$ range $(2$, LDLL-1dnlr, Figure 1). ${ }^{12}$ Moreover, Portola Pharmaceuticals has patented some tetrahydroisoquinolines $(\mathbf{3}, \text { Figure } 1)^{13}$ that increase the LDL uptake into liver cells and LDLR cell surface populations. Similarly, by a virtual screening session, Min and coworkers have identified compound 4 (or CB_36, Figure 1), ${ }^{14}$ containing fragments structurally resembling the plasticizer 2,2-bis(4-hydroxyphenyl)propane (5, BPA). However, these studies did not report any direct evidence that such small molecules bind PCSK9, so that 
they could instead act via another mechanism, such as PCSK9 modulators. Similarly, compound 6 (RIMPP or PF-00932239, Figure 1), as well as its analogs developed by Pfizer, act as antisecretagogues, lowering PCSK9 secretion by liver cells. Unfortunately, however, they are endowed with severe hematopoietic side effects. ${ }^{15,16}$ As recently reviewed by Xu et al., ${ }^{14}$ no substantial advancement in the discovery of PCSK9 small-molecule inhibitors has been made so far. Therefore, the therapy by PCSK9 mAbs remains the most advanced treatment for hypercholesterolemia.

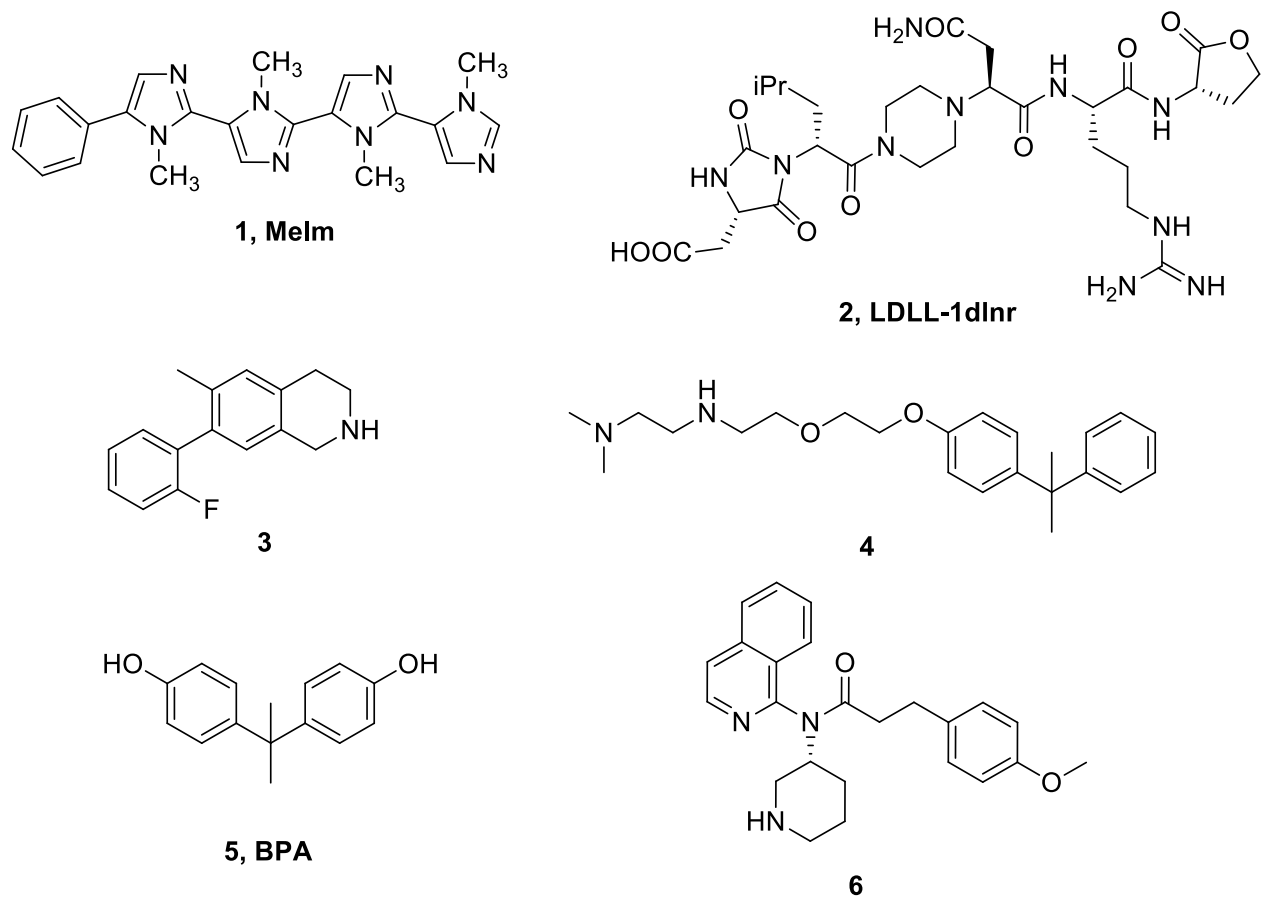

Figure 1. Chemical structures of small molecules endowed with PCSK9 inhibitory activity.

Given this scenario, the present study presents a detailed investigation on some new small molecules capable of inhibiting PCSK9. Specifically, the objective was to improve the biological activity of MeIm (1) by substituting the imidazole $N$-methyl groups with new moieties, suitably designed by a target-based computational approach. In order to avoid the expensive and time-consuming synthesis and biological characterization of compounds clearly showing low computed affinity, only the compounds showing the highest estimated affinity to PCSK9 were targeted for the experimental work. On the synthesized compounds, biological studies ranging from the inhibition of the PCSK9-LDLR binding to the evaluation of cell safety were performed. In addition, in order to evaluate the potential hypocholesterolemic activity, the most promising compounds were investigated for assessing their ability to modulate the LDLR expression on human hepatic HepG2 cells surface and to increase the capacity of the same cells to uptake extracellular LDL. 


\section{RESULTS AND DISCUSSION}

General overview of the design strategy. To improve the biological activity of MeIm by applying a rational target-based computational approach, the first step involved the assessment of the MeIm binding mode. Toward this aim, three replicas of "supervised Molecular Dynamics" (suMD) simulations were performed. ${ }^{17-20}$ This algorithm simulates the ligand binding process in an accessible time scale, monitoring the distance between the ligand atoms and the protein binding site during classical MD simulations without the introduction of biases or external forces. Successively, a cluster analysis algorithm was applied to the attained trajectory frames. Molecular Mechanics/Generalized-Born Surface Area (MM-GBSA) permitted us to choose the suMD replica in which the ligand showed the highest binding free energy and, reasonably, the most reliable binding mode. Starting from these data, the focused substitution of the $\mathrm{N}$-methyl groups exposed by the imidazole rings of MeIm was undertaken in the rational design of a small set of new MeIm analogs (RIm compounds). Finally, MD simulations and ligand binding free energy calculations, via the MM-GBSA approach, were used to select the compounds eligible for synthesis and further biological evaluation (Figure 2).

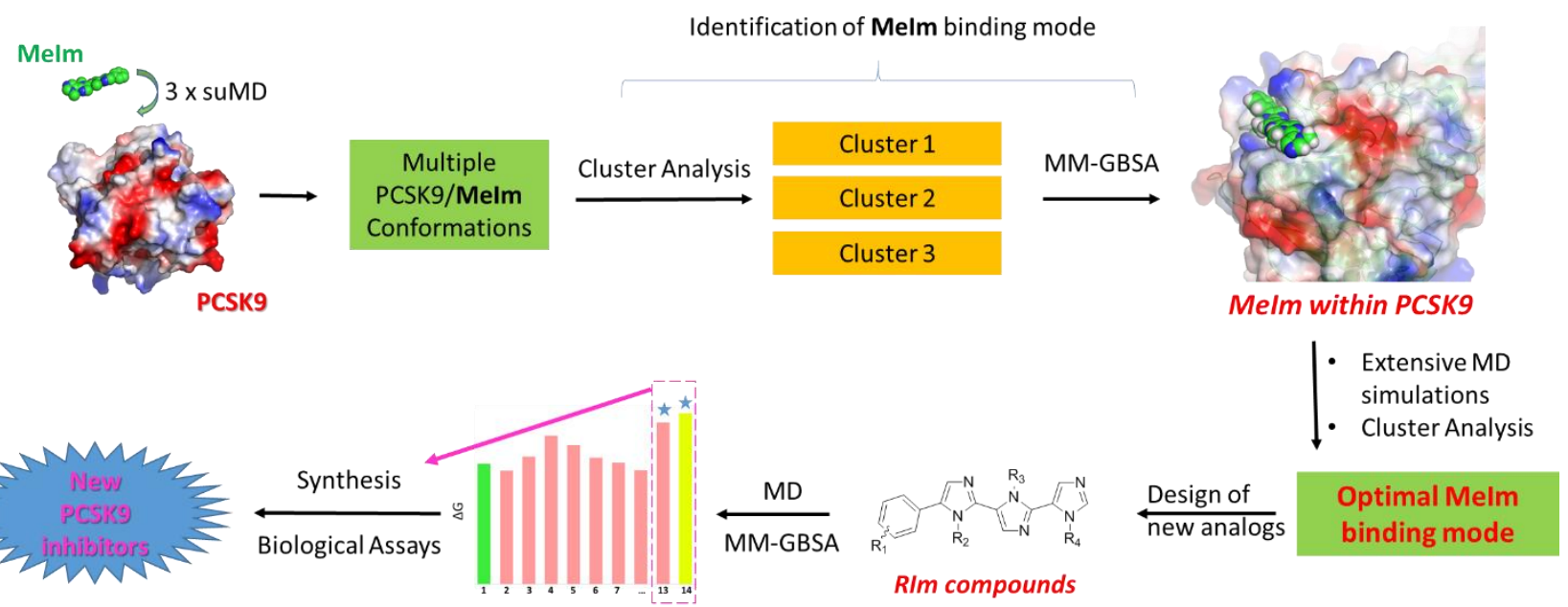

Figure 2. Workflow of the computational approach applied to select the best MeIm analogs for the synthesis and the biological evaluation.

suMD simulations. The MeIm binding process was determined by performing suMD simulations. ${ }^{17-20}$ The PCSK9 area involved in the interaction with the EGF-A domain of LDLR was considered as the target for ligand binding. ${ }^{21}$ Briefly, by a tabu-like algorithm, the suMD methodology exploits the distance between the centers of mass of the ligand atoms and the protein binding site during reiterated short MD simulations of $0.6 \mathrm{~ns}$. MD simulations were performed until the ligand-target distance repeatedly reaches 
values within the interval of $2-5 \AA$. The suMD simulation runs can be examined by a graph in which the suMD step (or the ligand interaction energy) and the distance between the ligand and the binding site are plotted (Figure S1A, Supporting Information). As suggested by the suMD developers, the suMD simulations were repeated three times. ${ }^{18}$ Then, cluster analysis was applied to extract the conformations representative of each suMD replica to assess the convergence of the attained results. In detail, the MD frames were divided into clusters by the complete average linkage algorithm, ${ }^{22}$ and the complex conformations with the lowest root mean square deviation (RMSD) to the cluster centers were visually inspected. By our simulations, each suMD replica showed a diverse MeIm binding mode. Thus, to choose the most consistent binding pose, MM-GBSA calculations were performed on the most populated clusters of conformations found in each replica. In fact, we argued that the MeIm preferred binding mode could be found in the suMD replica in which the ligand showed the lowest binding free energy value and in the highest populated cluster. This would also indicate that the ligand rested in an energy minimum of the system free energy landscape. More specifically, in the complex conformations of replica 2, MeIm was more tightly bound to PCSK9 (Figure S1B, Supporting Information). Nevertheless, to better sample the conformational space of the PCSK9/MeIm complex, $1 \mu$ s-long classical MD simulations were performed on the PCSK9/MeIm complex retrieved from this replica. Interestingly, by monitoring the PCSK9/MeIm contacts (Table S1, Supporting Information), these simulations excluded any ligand unbinding events, confirming that the MeIm conformers fluctuated within a minimum of the potential energy surface. However, the visual inspection of the MD trajectory and the RMSD plot (Figure 3A) led us to suspect that MeIm could adopt different binding modes within PCSK9. Thus, to explore the structural differences among them, hierarchical agglomerative cluster analysis was once more applied to identify the most representative modes (Figures 3B and Figure S2, Supporting information). The attained data evidenced that in the most populated cluster of conformations (59\% of frames, Figure 3B), MeIm was anchored on a PCSK9 $\beta$-strand shaped by residue C378-S381, while a cation- $\pi$ stacking between the phenyl ring of MeIm and the side chain of residue PCSK9-R194 may additionally stabilize the ligand on the PCSK9 surface. Considering that the binding mode found in the first cluster was the most preferred by MeIm, the design of new analogs was accomplished by considering the representative complex conformation of this cluster as the design template. 

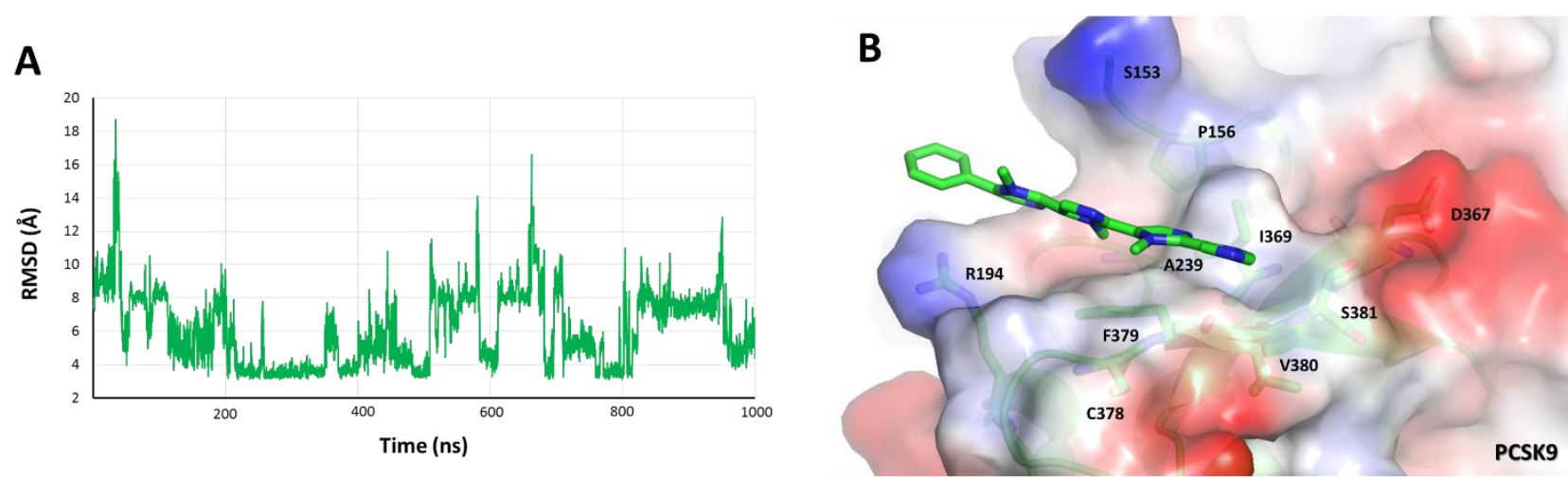

Figure 3. A) RMSD plot of MeIm heavy atoms with respect to their average structure. The PCSK9 backbone atoms were previously aligned with respect to the initial minimized structure. B) Representative structural clusters of MeIm as a result of clustering the MD trajectory frames. MeIm is represented as sticks, whereas the PCSK9 surface area is colored according to atomic partial charges: positive and negative areas are colored blue and red, respectively. These figures were acquired by Pymol software (Schrödinger Inc., USA).

Design of novel MeIm analogs. Initially, to increase the synthetic feasibility and to obtain ligands bearing a molecular weight lower than $500 \mathrm{Da}$ (as stated by Lipinski rules), the new MeIm analogs (named RIm compounds) contained only one phenyl ring bound to a chain of three suitably substituted imidazole rings.

In principle, the moieties decorating the imidazole rings of the RIm compounds should show the highest structural complementarity with the biological counterpart with which they directly interact. For this reason, when examining the PCSK9 site involved in the LDLR recognition (Figure 4), we thought that the PCSK9 inhibitors could exploit at least four regions: (i) the positively charged area close to K237 and R194; (ii) the hydrophobic pocket sized by I369, A239, F379, L158; (iii) the negatively charged area close to D367; and (iv) the planar hydrophobic area enclosing the $\beta$-strand-shaped residues C378-S383 (Figure 4). 


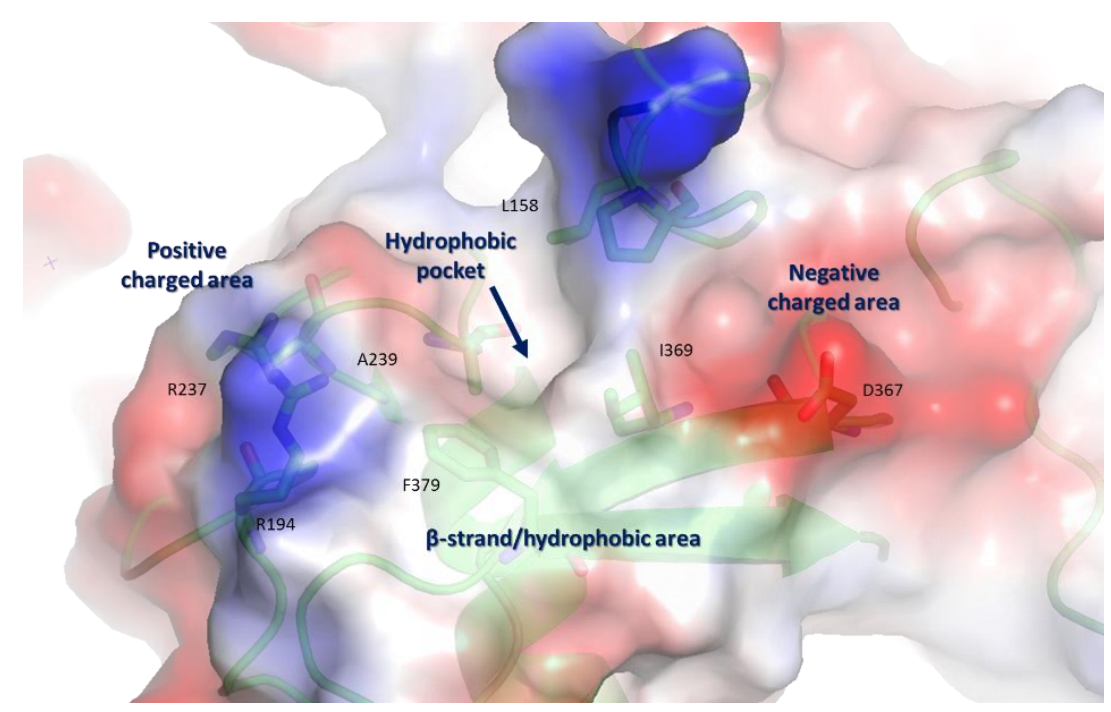

Figure 4. PCSK9 surface exploited for drug design approach. The enzyme solvent-accessible surface is depicted according to the partial charge of the residues, blue for positive and red for negative areas.

Taking into account these information, MeIm could interact with the positive charged area, the hydrophobic pocket (though the methyl group could occupy it partially), and the $\beta$-strand/hydrophobic area. At variance, the optimal inhibitor should putatively involve all the above-described areas.

Therefore, starting from the previously selected PCSK9/MeIm complex conformation, a small set of compounds was rationally designed (see experimental section for details) by considering the following assumptions:

- compounds RIm1 and RIm2, bearing a meta- or a para-methoxy group on the phenyl ring, were designed to increase the electron density of the benzene ring, considering that it was in contact with the PCSK9 positively charged residue R194.

- by compounds RIm3-RIm4, we explored substituents showing chemical properties different from those of an aliphatic group of the first imidazole ring. For simplicity, we did not introduce any additional modification of the methyl group since, in the most populated MeIm conformations cluster, $\mathrm{R}_{2}$ was immersed in solvent molecules and did not show any contact with PCSK9.

- substituents in the second imidazole ring of compounds RIm5-RIm7 pointed to occupy the PCSK9 pocket shaped by PCSK9 residues I369, A239, L158, and F379.

- compounds RIm8-RIm12 were designed to promote the creation of a hydrogen bond/salt bridge between the third imidazole ring of the inhibitors and the PCSK9 negatively charged area shaped by the side chain of D367.

- compound RIm13 was designed to improve the basicity of the amine group of compound RIm12, aiming to better stabilize the salt-bridge interaction. 
- compound RIm14 was finally inserted into this set of molecules as an attempt to assess the effects triggered by $\mathrm{R}_{2}$ homologation on RIm13.

The PCSK9/RIm $(n)$ complexes were created by using the editing tools available in the Maestro software (Schrödinger Inc., USA). Geometry optimization, 100 ns-long MD simulations, and MM-GBSA calculations performed on the attained complexes permitted the estimation of the binding free energy values $\left(\Delta \mathrm{G}^{*}\right)$ of these compounds (Table 1), with the aim of sorting out which compound was the most theoretically active for further experimental evaluation.

Table 1. Chemical structure of the compounds considered in this study and their calculated binding free energy values $\left(\Delta \mathrm{G}^{*}\right.$, column 6). $\Delta \Delta \mathrm{G}^{*}$ values (column 7) represent the difference between the theoretical binding free energy value of MeIm and those calculated for new derivatives.

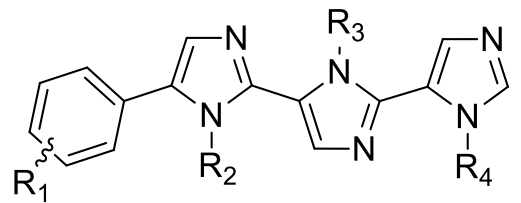

\begin{tabular}{|c|c|c|c|c|c|}
\hline Compound & $\mathbf{R}_{1}$ & $\mathbf{R}_{2}$ & $\mathbf{R}_{3}$ & $\mathbf{R}_{4}$ & $\begin{array}{c}\Delta \mathbf{G}^{\boldsymbol{*}} \\
(\mathrm{kcal} / \mathrm{mol} \pm \text { Std. Err. of Mean })\end{array}$ \\
\hline MeIm & & & & & $-17.5 \pm 0.4$ \\
\hline RIm1 & $-3-\mathrm{OCH}_{3}$ & $-\mathrm{CH}_{3}$ & $-\mathrm{CH}_{3}$ & $-\mathrm{CH}_{3}$ & $-11.9 \pm 0.5$ \\
\hline RIm2 & $-4-\mathrm{OCH}_{3}$ & $-\mathrm{CH}_{3}$ & $-\mathrm{CH}_{3}$ & $-\mathrm{CH}_{3}$ & $-16.2 \pm 0.2$ \\
\hline RIm3 & $-4-\mathrm{OCH}_{3}$ & $-\mathrm{NH}_{2}$ & $-\mathrm{CH}_{3}$ & $-\mathrm{CH}_{3}$ & $-11.8 \pm 0.2$ \\
\hline RIm4 & $-4-\mathrm{OCH}_{3}$ & $-\mathrm{COOH}$ & $-\mathrm{CH}_{3}$ & $-\mathrm{CH}_{3}$ & $-13.0 \pm 0.3$ \\
\hline RIm5 & $-4-\mathrm{OCH}_{3}$ & $-\mathrm{CH}_{3}$ & $-\mathrm{CH}_{2} \mathrm{Ph}$ & $-\mathrm{CH}_{3}$ & $-19.7 \pm 0.3$ \\
\hline RIm6 & $-4-\mathrm{OCH}_{3}$ & $-\mathrm{CH}_{3}$ & $-\mathrm{CH}_{2} \mathrm{Naph}$ & $-\mathrm{CH}_{3}$ & $-17.0 \pm 0.4$ \\
\hline RIm7 & $-4-\mathrm{OCH}_{3}$ & $-\mathrm{CH}_{3}$ & $-\mathrm{CH}_{2}-4 C l \mathrm{Ph}$ & $-\mathrm{CH}_{3}$ & $-15.2 \pm 0.3$ \\
\hline RIm8 & $-4-\mathrm{OCH}_{3}$ & $-\mathrm{CH}_{3}$ & $-\mathrm{CH}_{2} \mathrm{Ph}$ & $-\mathrm{CH}_{2}-\mathrm{NH}_{2}$ & $-15.8 \pm 0.5$ \\
\hline RIm9 & $-4-\mathrm{OCH}_{3}$ & $-\mathrm{CH}_{3}$ & $-\mathrm{CH}_{2} \mathrm{Ph}$ & $-\left(\mathrm{CH}_{2}\right)_{2}-\mathrm{NH}_{2}$ & $-18.0 \pm 0.2$ \\
\hline RIm10 & $-4-\mathrm{OCH}_{3}$ & $-\mathrm{CH}_{3}$ & $-\mathrm{CH}_{2} \mathrm{Ph}$ & $-\left(\mathrm{CH}_{2}\right)_{3}-\mathrm{NH}_{2}$ & $-18.3 \pm 0.4$ \\
\hline RIm11 & $-4-\mathrm{OCH}_{3}$ & $-\mathrm{CH}_{3}$ & $-\mathrm{CH}_{2} \mathrm{Ph}$ & $-\left(\mathrm{CH}_{2}\right)_{4}-\mathrm{NH}_{2}$ & $-14.7 \pm 0.3$ \\
\hline RIm12 & $-4-\mathrm{OCH}_{3}$ & $-\mathrm{CH}_{3}$ & $-\mathrm{CH}_{2} \mathrm{Ph}$ & $-\left(\mathrm{CH}_{2}\right)_{5}-\mathrm{NH}_{2}$ & $-18.9 \pm 0.3$ \\
\hline RIm13 & $-4-\mathrm{OCH}_{3}$ & $-\mathrm{CH}_{3}$ & $-\mathrm{CH}_{2} \mathrm{Ph}$ & $-\left(\mathrm{CH}_{2}\right)_{5}-\mathrm{NH}-\mathrm{CH}_{3}$ & $-22.9 \pm 0.3$ \\
\hline Rim14 & $-4-\mathrm{OCH}_{3}$ & $-\mathrm{CH}_{3}$ & $-\mathrm{CH}_{2} \mathrm{CH}_{2} \mathrm{Ph}$ & $-\left(\mathrm{CH}_{2}\right)_{5}-\mathrm{NH}-\mathrm{CH}_{3}$ & $-22.1 \pm 0.5$ \\
\hline P5 & & & & & $-18.9 \pm 0.5^{1}$ \\
\hline
\end{tabular}

${ }^{1}$ This value was estimated performing MM-GBSA calculations on 500 ns-long MD simulations on the PCSK9/P5 complex described on reference 21 .

The results in Table 1 suggest that: 1) the $p$-methoxy was better than $m$-methoxy group as R1 substituent; 2) the amino- and carboxy- groups, as R2 substituent, reduced the calculated affinity of the resulting compounds; 3) the benzyl group, as R3 substituent, was better than the other selected moieties in the 
interaction with the PCSK9 hydrophobic cavity; 4) the alkyl-amino chains, as R4 substituents, containing less than five methylene groups, were not capable to reach the negatively charged area on the PCSK9 surface; 4) the terminal -NH-Me group, as R4 substituent, led to a compound (RIm13) with a computed affinity $3 \mathrm{kcal} / \mathrm{mol}$ lower than that of RIm12; 5) the homologation of the benzyl group on Rim13 did not lead to the improvement of the computed $\Delta \mathrm{G}^{*}$ value, since the one of Rim14 was slightly lower than that of RIm13. Consequently, it was possible thinking that the benzyl group was optimal for the interaction with the hydrophobic cavity on the PCSK9 surface.

In the light of these outcomes, RIm13 and RIm14 possessed the lowest estimated binding free energy on PCSK9. For them, additional MD simulations were performed to gain accurate insights into their binding mechanism. Toward this aim, MD simulations were run to $1 \mu$ s, and cluster analysis was subsequently performed. Then, MM-GBSA calculations were accomplished on the trajectory frames found in the most populated clusters of complex conformations. By these, $\Delta \mathrm{G}^{*}$ values of $-22.1 \pm 0.5$ and $-19.5 \pm 0.6 \mathrm{kcal} / \mathrm{mol}$ were attained for RIm13 and RIm14, respectively. The theoretical affinity of both compounds remained higher than that of MeIm; moreover, RIm13 showed the lowest estimated $\Delta \mathrm{G}^{*}$ value.

In the complex conformation representative of the most populated cluster (55\% of frames), RIm13 (Figure 5A) was bound to PCSK9 by (1) creating a H-bond/salt bridge by the amino group with the PCSK9 D367 residue, (2) projecting the benzyl ring in the hydrophobic pocket sized by A239, F379, P156, and I369, and (3) generating a cation- $\pi$ stacking by the third imidazole ring with the $N$-terminal end of PCSK9 (S153). Remarkably, this putative binding mode showed high stability over MD simulations, as demonstrated by monitoring the contacts between PCSK9 and the ligand atoms (see Table S2, Supporting Information).

On the other hand, the PCSK9 residues involved in the interaction with RIm14 were essentially similar to those previously described for RIm13, although the frequency of the contacts (Table S3, Supporting information) decreased. Nevertheless, the theoretical binding mode of RIm14 (Figure 5B) that resulted in the cluster of conformations populated by the majority of trajectory frames (43\%) was different from RIm13. The difference was found in the position of the phenyl ring, creating cation- $\pi$ stacking with the PCSK9 N-terminal end (S153), and in the formation of a salt bridge with D374. Moreover, the phenethyl moiety in RIm14 seemed too large to be accepted in the hydrophobic pocket sized by A239, F379, P156, and I369 (Figure 5B), since it fluctuated in the solvent environment from 
the early stages of MD simulations. Additionally, the overall stability of RIm14 on the PCSK9 surface was lower than that of RIm13, as expected by the RMSD plot (Figure S3, Supporting information).
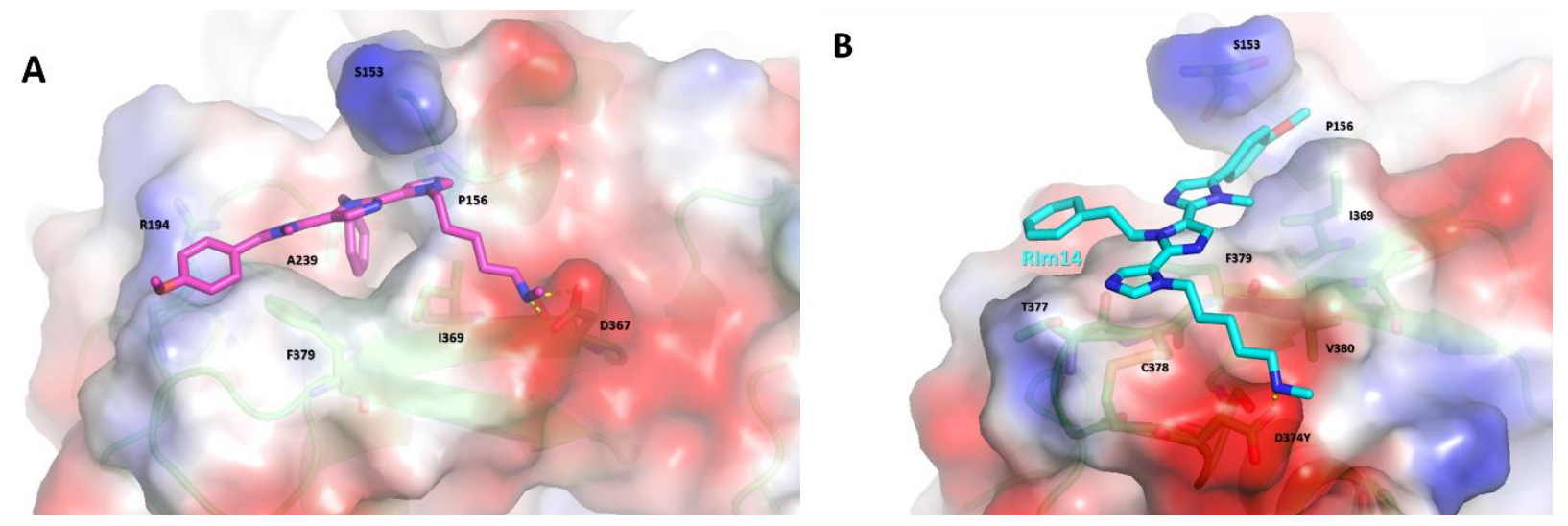

Figure 5. Hypothetical orientation of RIm13 (A, magenta sticks) and RIm14 (B, cyan sticks) on the PCSK9 surface. The enzyme is represented as green sticks highlighting the secondary structure. The solvent-accessible surface of PCSK9 is colored depending on the partial charge of the atoms: positive areas are depicted as blue, while red areas suggest the presence of positively charged residues. H-bonds are represented as yellow dashed lines.

Based on these assumptions, compounds RIm13 and RIm14 were synthesized and experimentally assayed to evaluate their biological activity. Together with these, a synthetic intermediate (compound $\mathbf{9}$, see the next section) was also tested in order to evaluate the effects of the presence of the third imidazole ring on the biological activity of compounds RIm13.

Synthesis of compounds RIm13 and RIm14. The targeted compounds RIm13 and RIm14 were synthesized through a quasi-iterative process, pivoted on the alternation of van Leusen three-component reactions (vL-3CRs) with formylation steps. The vL-3CR is able to generate trisubstituted imidazoles in a single step, by a base-induced condensation between an aldehyde, a primary amine and tosylmethyl isocyanide (TosMIC). This chemical path was conceived for ensuring the rapid construction of functionalized triimidazole derivatives, exposing different $\mathrm{N}$-substituents on imidazole rings. The proper choice of amine components for the three sequential vL-3CRs allowed determining such N-substituents. Formylation at C-2 of imidazole intermediates furnished step by step the required aldehyde components, besides the starting p-anisaldehyde (Scheme 1). 


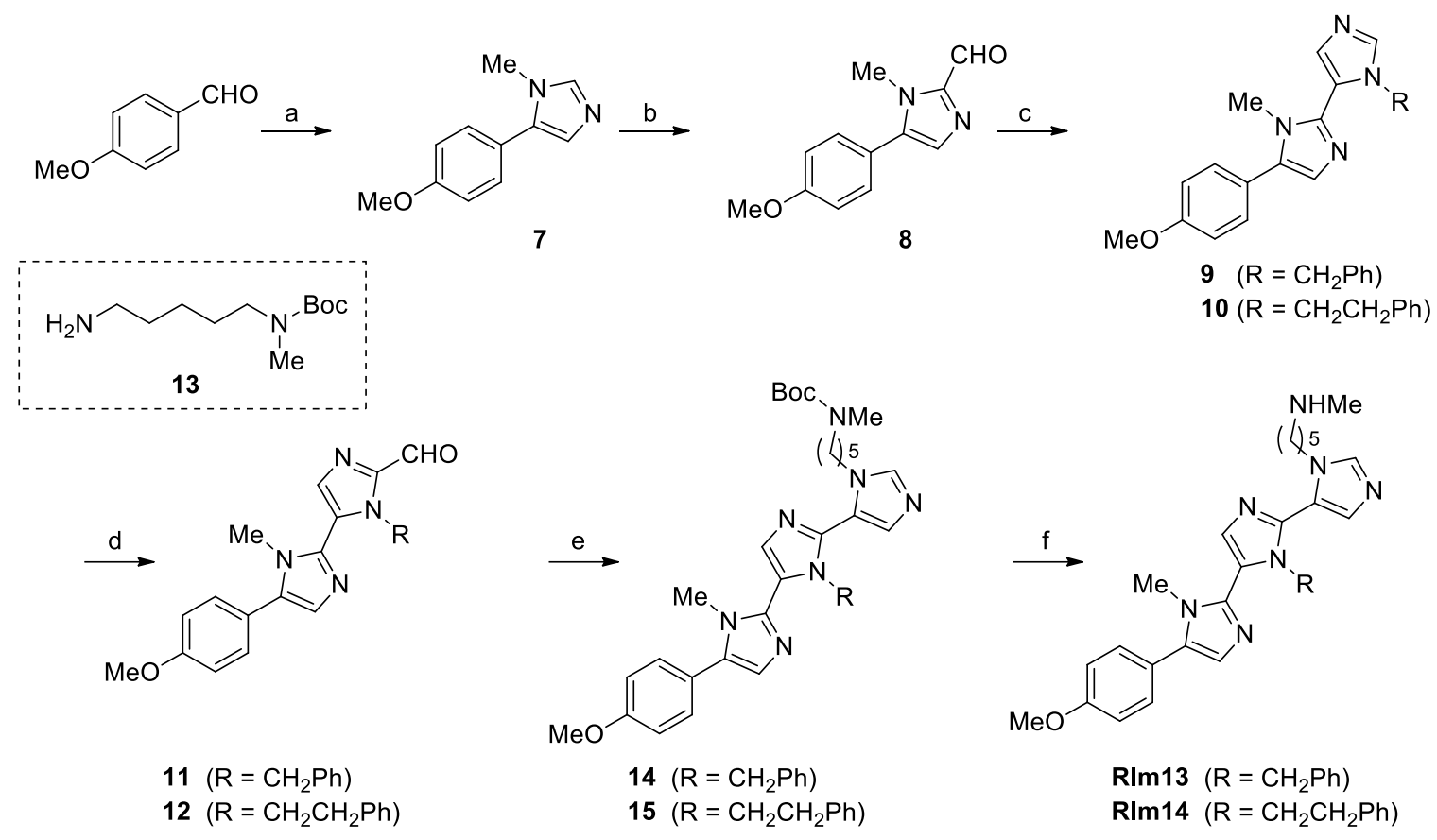

Scheme 1. Reagents and conditions: a) $\mathrm{MeNH}_{2} 40 \mathrm{wt} \%$ aq sol, DMF, rt, $2 \mathrm{~h}$; then TosMIC, $\mathrm{K}_{2} \mathrm{CO}_{3}, 50{ }^{\circ} \mathrm{C}, 3 \mathrm{~h}(82 \%)$. b) $\mathrm{n}$ $\mathrm{BuLi}, \mathrm{THF},-78^{\circ} \mathrm{C}, 2 \mathrm{~h}$; then DMF, rt, $2 \mathrm{~h}(77 \%)$. c) Benzylamine (for 9) or phenethylamine (for 10), DMF, $70^{\circ} \mathrm{C}, 2 \mathrm{~h}$; then TosMIC, $\mathrm{K}_{2} \mathrm{CO}_{3}, 70{ }^{\circ} \mathrm{C}$, overnight ( $48 \%$ for $9,45 \%$ for 10 ). d) $n$-BuLi, TMEDA, THF, $-78{ }^{\circ} \mathrm{C}, 2 \mathrm{~h}$; then DMF, rt, $2 \mathrm{~h}(43 \%$ for $11,77 \%$ for 12). e) Amine 13, DMF, $70{ }^{\circ} \mathrm{C}$, $2 \mathrm{~h}$; then TosMIC, $\mathrm{K}_{2} \mathrm{CO}_{3}, 70{ }^{\circ} \mathrm{C}$, overnight ( $45 \%$ for $17,40 \%$ for 18 ). f) $4 \mathrm{~N}$ $\mathrm{HCl}$ in $\mathrm{AcOEt}$, from $0{ }^{\circ} \mathrm{C}$ to rt, overnight; then $\mathrm{NaHCO}_{3} / \mathrm{CH}_{2} \mathrm{Cl}_{2}$ (quant. yield for both $\mathbf{R I m 1 3}$ and $\mathbf{R I m 1 4}$ ).

In detail, the first imidazole derivative 7 was obtained in good yield, starting from $p$-anisaldehyde, methylamine and TosMIC. A precondensation time of $2 \mathrm{~h}$ ensured the in situ formation of the intermediate imine from $p$-anisaldehyde and methylamine, after that isocyanide was added. Then, compound 7 was treated with $n-\mathrm{BuLi}$ at low temperature and $\mathrm{DMF}$ as formylating agent, to give the aldehyde derivative $\mathbf{8}$ still in good yield. The subsequent vL-3CR employed benzyl amine or, alternatively, phenethylamine, besides compound $\mathbf{8}$ and TosMIC, and required a slightly higher temperature, affording the diimidazole derivatives $\mathbf{9}$ and $\mathbf{1 0}$ in moderate yield, after careful purification on neutral aluminum oxide. Formylation of compounds $\mathbf{9}$ and 10, to give $\mathbf{1 1}$ and $\mathbf{1 2}$ respectively, required the addition of TMEDA in order to facilitate the solubilization of intermediate lithium anions and then their reaction with DMF. The last vL-3CR needed the preliminary synthesis of amine 13, which was carried out as reported in Scheme S1 (Supporting Information).

From reaction of aldehyde derivatives 11 and 12 with amine 13 under standard vL-3CR conditions, the N-Boc protected triimidazole derivatives 14 and 15 were obtained. Finally, by acidic N-Boc deprotection, the target compounds RIm13 and RIm14 were achieved quantitatively. Their structure, as well as that of all intermediates, was confirmed through ${ }^{1} \mathrm{H}$ NMR, ${ }^{13} \mathrm{C}$ NMR and mass spectrometry. 
PCSK9-LDLR binding experiments. In order to evaluate the ability of compounds RIm13 and RIm14 to impair the PPI between PCSK9 and LDLR, in vitro binding experiments were performed. Both compounds were tested in a range of concentrations from 0.01 to $500.0 \mu \mathrm{M}$ (Figure 6A). Compounds RIm13 and RIm14 showed dose-response behaviors with $\mathrm{IC}_{50}$ values of $1.38 \pm 0.1$ and $3.06 \pm 0.3 \mu \mathrm{M}$, respectively. Compound $\mathbf{9}$, which was tested at the concentrations of 10.0 and $100.0 \mu \mathrm{M}$, was instead inactive, since, at the concentration of $100.0 \mu \mathrm{M}$, it impaired the PCSK9-LDLR binding by 18.2 $\pm 8.4 \%$, but in a non-statistically significant way (Figure 6B).
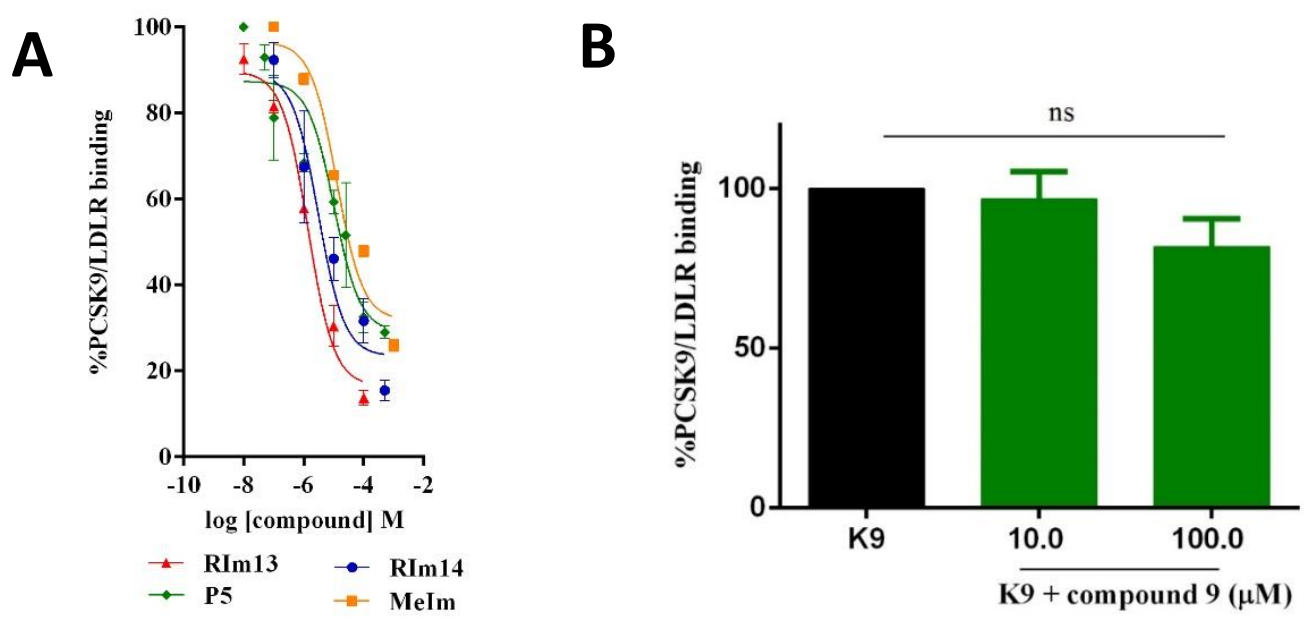

Figure 6. A) Inhibition of the PCSK9/LDLR PPI by compounds RIm13 (red curve), RIm14 (blue curve), MeIm (orange curve), and peptide P5 (green curve). $\mathrm{IC}_{50}$ values were equal to 1.4, 3.1, 11.2, and 1.6 $\mu \mathrm{M}$, respectively. Data points represent averages \pm s.d. of three independent experiments in duplicate. B) Compound 9 does not impair the PCSK9/LDLR PPI at 10.0 and $100.0 \mu \mathrm{M}$. Data points represent averages \pm s.d. of three independent experiments in duplicate. ns: not significative.

Remarkably, these data confirmed the previous theoretical predictions in favor of improved affinities of RIm compounds. In fact, RIm13 displayed an $\mathrm{IC}_{50}$ value 10 -fold lower than that of MeIm $(11.2 \mu \mathrm{M})^{10}$ and, accordingly, the RIm13-calculated $\Delta \mathrm{G}^{*}$ value was $5.4 \mathrm{kcal} / \mathrm{mol}$ lower than that of MeIm (Table 2). Moreover, the lower experimental and estimated affinity shown by RIm14 could be due to the different suspected binding mode and to the low stability of RIm14 in the PCSK9 binding site (RMSD plot, Figure S3, Supporting information). Interestingly, binding experiments on compound 9 suggested that the presence of the third imidazole ring in the structure of RIm13 is fundamental to the PCSK9 binding affinity of the compound. MD simulations accomplished on the PCSK9/9 complex showed the conformational instability of the ligand within the PCSK9 surface, this led rapidly to the ligand unbinding after just 45 ns of MD simulations. Considering the trajectory frames in which the ligand interacted with 
PCSK9, a $\Delta \mathrm{G}^{*}$ value of $7 \mathrm{kcal} / \mathrm{mol}(-15.0 \pm 0.3 \mathrm{kcal} / \mathrm{mol})$ lower than that of Rim13 was calculated for compound 9.

Characterization of the cholesterol-lowering effect of RIm13 on HepG2 cells. The 10-fold in vitro binding affinity exhibited by RIm13 prompted us to investigate more deeply the molecular and functional effects of PCSK9 inhibition on LDLR-pathway modulation. To achieve this goal, human hepatic HepG2 cells were chosen as the cell system of interest. Initially, viability experiments (MTT) were performed in order to exclude any potential cytotoxicity effect after the treatment of HepG2 cells with increasing concentrations $(0.1,1.0$, and $10.0 \mu \mathrm{M})$ of the compound RIm13. The attained results suggested that RIm13 was safe for the HepG2 cells (Figure S4, Supporting Information), therefore these concentrations were used for the further biological characterization of RIm13. Afterwards, the effects of compound RIm13 on the modulation of the LDLR localized on the HepG2 cell surface were investigated using an in cell western (ICW) assay. ${ }^{23}$ These experiments clearly indicated that the LDLR protein levels decreased in the presence of PCSK9 alone by $30.5 \pm 4.4 \%$ versus the control cells, and that compound RIm13 (at the fixed concentration of $1.0 \mu \mathrm{M}$ ) enhances the LDLR protein levels when co-incubated with PCSK9. These experiments were performed using peptide P5 (positive control) and 9 (negative control) as reference ligands at the fixed concentration of 1.0 and $10.0 \mu \mathrm{M}$, respectively (Figure 7A). More in details, HepG2 cells incubated with PCSK9 and RIm13 $(1.0 \mu \mathrm{M})$ renewed the LDLR on cell membrane up to $88.4 \pm 3.7 \%$, similarly to the positive control peptide P5, which restored the receptor protein level up to $93.9 \pm 4.8 \%$. On the contrary, the compound 9 (negative control) was not able to reestablish the LDLR levels, suggesting that compound RIm13 is an effective PCSK9 inhibitor. Based on these results, new ICW experiments were assessed testing RIm13 at 0.1, 1.0, and 10.0 $\mu \mathrm{M}$. In particular, Figure 7B clearly indicates that the LDLR levels dropped in the presence of PCSK9 alone by $47.2 \pm 12.2 \%$ versus the control cells, and that increased the LDLR protein levels when co-incubated with PCSK9. In particular, HepG2 cells incubated with PCSK9 and $\operatorname{RIm13}(0.1,1.0$, and $10.0 \mu \mathrm{M})$ restored the LDLR up to $77.7 \pm 15.7 \%, 101.2 \pm 21.8 \%$, and $101.6 \pm 14.8 \%$, respectively, indicating a concentration-response dependence (Figure 7B).

Moreover, functional experiments were carried out in order to evaluate the ability of the new compound to modulate the capacity of HepG2 cell to uptake extracellular LDL. At the beginning, HepG2 cells were treated with PCSK9 alone or in the presence of the new and references compounds (9 and P5), respectively. After $2 \mathrm{~h}$ of treatment with PCSK9 alone, a reduced ability of HepG2 cells to uptake fluorescent LDL by $34.8 \pm 7.2 \%$ versus untreated cells was achieved (Figure 7C). Unlike to compound 
9 (negative control), compound RIm13, tested at the fixed concentration of $1.0 \mu \mathrm{M}$ restored the LDLuptake up to $103.7 \pm 17.3 \%$ similarly to peptide P5 that, at the same concentration, increase the ability of hepatic cells to absorb LDL up to $103.5 \pm 13.5 \%$ (Figure 7C). Moreover, as showed in the Figure 7D, the treatment with PCSK9 alone reduced the capability of HepG2 cells to clear the fluorescent LDL by $67.0 \pm 4.5 \%$ versus untreated cells was observed (Figure 7D); however, this ability was improved by RIm13 at all tested concentrations. In particular, RIm13, at the concentrations of 0.1, 1.0, and 10.0 $\mu \mathrm{M}$, improved the LDL uptake by $63.6 \pm 12.8 \%, 95.7 \pm 15.5 \%$, and $101.0 \pm 24.1 \%$, respectively.

A

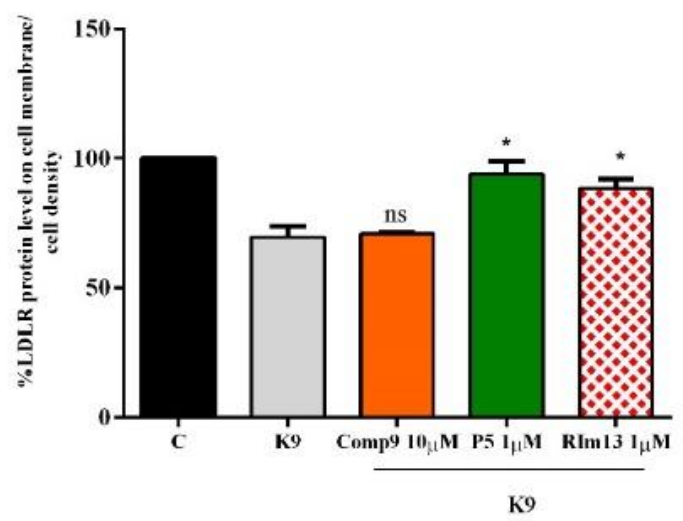

C

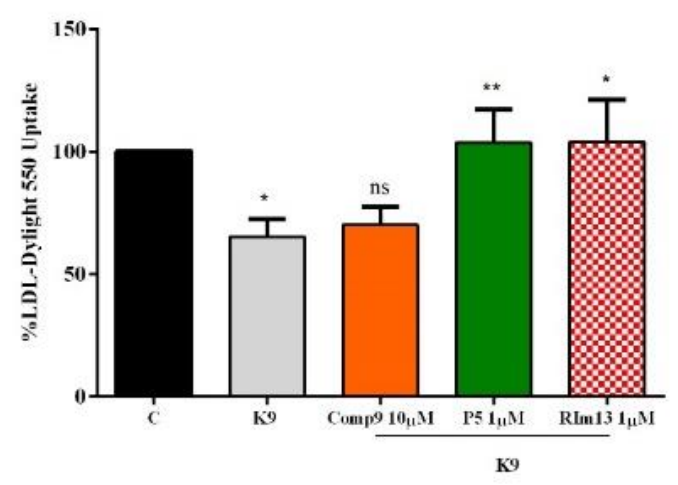

B

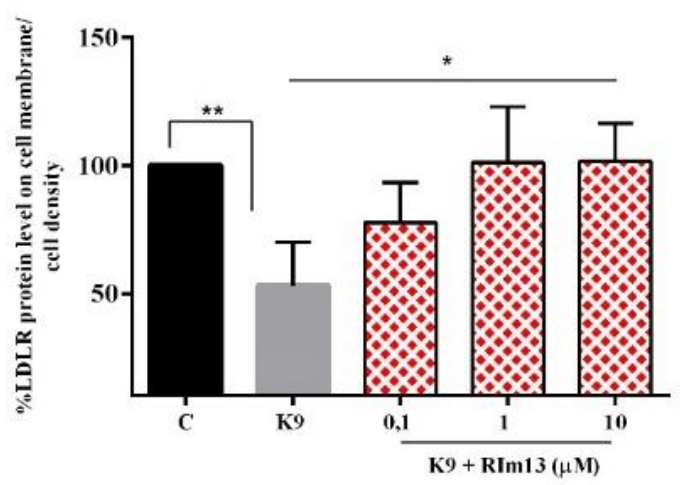

D

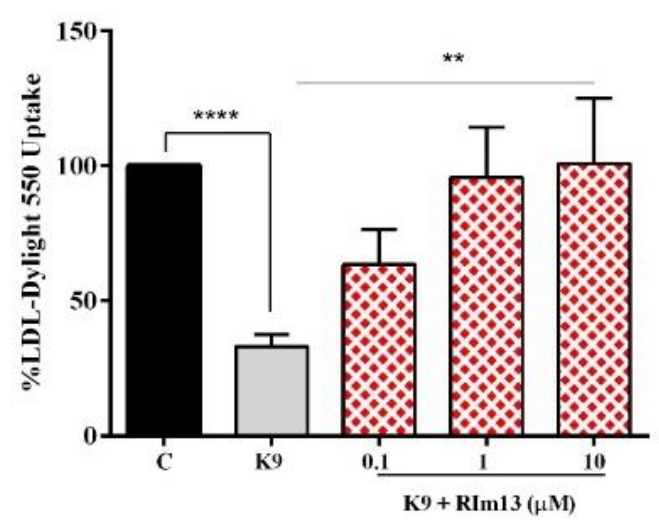

Figure 7. A) RIm13 at the fixed concentration of $1.0 \mu \mathrm{M}$, increases the LDLR protein level on cell membrane similarly to peptide P5 $(1.0 \mu \mathrm{M})$, whereas compound 9 was unable to modulate the active LDLR protein; B) RIm13 induces an increase of the LDLR protein level on the HepG2 cell surface. LDLR degradation mediated by PCSK9 (K9) is prevented by increasing concentrations of $\operatorname{RIm13}(0.1,1.0$, and $10.0 \mu \mathrm{M})$. C) $\operatorname{RIm13}(1.0 \mu \mathrm{M})$ restores the ability of HepG2 to clear LDL from extracellular environment similar to the positive control, P5 (1.0 $\mu \mathrm{M})$, on the contrary, compound $\mathbf{9}$ was ineffective to modulate the functional ability of hepatic cells; D) The decreased ability to uptake LDL by HepG2 cells mediated by K9 is prevented by increasing concentrations of RIm13 $(0.1-10.0$ $\mu \mathrm{M})$. C represents the control without any treatment. Results are mean \pm s.d. of three independent experiments. (*) $P<0.05,(* *) P<0.001$, and $(* * * *) P<0.00001$. 


\section{CONCLUSIONS}

We applied an integrated computational approach, including suMD, MD simulations, cluster analysis, and binding free energy estimation (MM-GBSA), to investigate the binding mechanism of the polyimidazole peptidomimetic MeIm to PCSK9. Starting from this information, a small set of compounds (Table 3) were suitably designed by means of molecular modeling tools and a structure-based drug design methodology. Then, MD simulations and MM-GBSA calculations were performed on this set of compounds to select the most promising terms for further chemical synthesis and biological evaluation of PCSK9. This computational procedure avoided the costly synthesis and biological characterization of compounds with low computed affinity. Therefore, compounds RIm13 and Rim14 appeared to be particularly interesting, since they displayed the highest estimated binding affinity to PCSK9. The consequent synthesis, by van Leusen three-component reactions, and the experimental binding affinity assays confirmed the theoretical predictions. In fact, RIm13 exhibited an improved inhibitory activity on the PCSK9/LDLR PPI, displaying an $\mathrm{IC}_{50}$ value 10-fold lower than the template compound MeIm. Remarkably, at the concentration of $1 \mu \mathrm{M}, \mathbf{R I m} 13$ prevented the LDLR degradation mediated by PCSK 9 on HepG2 cells (Figure 7B), as well as increased the LDL uptake at the same concentration (Figure 7C). To the best of our knowledge, RIm13 represents currently one of the most potent small molecules targeting the PCSK9/LDLR PPI. The attained results confirm that the computer-aided design of PCSK9 inhibitors can reliably guide the drug discovery process.

\section{EXPERIMENTAL SECTION}

General Methods. All commercial materials and solvents (> 95\% purity grade) was used without further purification. All reactions were carried out under a nitrogen atmosphere, unless otherwise noted. All reactions were monitored by thin layer chromatography (TLC) on precoated silica gel 60 F254; spots were visualized with UV light or by treatment with a $1 \%$ aqueous $\mathrm{KMnO}_{4}$ solution or $0.2 \%$ ninhydrin solution in ethanol. Products were purified by flash chromatography (FC) on silica gel 60 (230-400 mesh) or aluminium oxide activated neutral 58 (150 mesh). NMR spectra were recorded on 300 or 400 $\mathrm{MHz}$ Bruker spectrometers, using tetramethylsilane (TMS) as the internal standard. For ${ }^{13} \mathrm{C}$ NMR, the APT pulse sequence was adopted. Chemical shifts are reported in parts per million relative to the residual solvent. Multiplicities in ${ }^{1} \mathrm{H}$ NMR are reported as follows: $\mathrm{s}=$ singlet, $\mathrm{d}=$ doublet, $\mathrm{t}=$ triplet, $\mathrm{m}=$ multiplet, br s = broad singlet. The mass spectra were obtained in the ESI positive mode ((+)-HRESIMS), from a Waters Micromass Q-Tof micro Mass spectrometer. 
The purity of tested compounds was confirmed to be $>95 \%$ by means of elemental analysis on a CHN Perkin - Elmer 2400 instrument. To exclude any spectroscopic interference by compounds with LDL uptake cell-based test, fluorescence assays have been conducted. Moreover, the chemotypes found in our compounds do not belong to Pan Assay Interference Compounds (PAINS), as confirmed by ZINC server (http://zinc15.docking.org/patterns/home).

System setup, suMD, and classical MD simulations. After retrieving the X-ray coordinate from the Protein Data Bank (PDB code 4NMX, resolution $1.85 \AA$ ), ${ }^{24}$ we built and optimized the PCSK9 computational model. The model was successfully utilized to perform several studies on natural and synthetic peptides. ${ }^{21,25,26}$ Here, it was initially used to perform suMD simulations ${ }^{20}$ and to predict the MeIm binding mechanism. The atomic partial charges of MeIm, as well as the charges of the new compounds, were assigned by RESP calculations, ${ }^{27}$ as implemented in an antechamber. The applied MD simulation protocol have been described by us. ${ }^{21,26} \mathrm{FF} 4 \mathrm{SB}^{28}$ and $\mathrm{GAFF}^{29}$ force fields were used to parameterize the complexes studied by the suMD algorithm and classical MD simulations. The default parameters were set in the suMD configuration file (selection.dat), and the 0.91 version of this algorithm was employed for these calculations. ${ }^{18}$ The ligand binding site on PCSK9 was the site shaped by residues depicted by the presence of the EGF-A domain of LDLR in the X-ray structure (P155, R194, A239, T377, F379, Q382). ${ }^{30}$ SuMD simulations were performed by the support ACEMD ${ }^{31}$ as an algorithm for classical MD simulations. The $1 \mu$ s-long production runs of MD simulations performed on PCSK9 in the complex with MeIm, RIm13, and RIm14 were performed by pmemd.cuda modules of the Amber17 package. $^{32}$ The MD trajectories were examined by visual inspection with VMD. ${ }^{33}$

Cluster analysis. Cluster analysis of the trajectory coordinates attained by suMD and classical MD simulations on PCSK9/MeIm, PCSK9/RIm13, and PCSK9/RIm14 complexes were achieved via the hierarchical agglomerative approach, with an average complete linkage algorithm. The Cpptraj module ${ }^{34}$ of Amber $17^{32}$ was used toward this aim. The default parameters were used to process each trajectory file, and the conformation with the lowest RMSD to the cluster center was examined and discussed in the above sections. The RMSD of the ligand heavy atoms were used as a distance metric.

Ligand binding free energy estimation. The MM-GBSA approach was applied to estimate the ligand binding free energy values. Once the geometrical stability of the ligand under investigation was acquired, i.e., the ligand RMSD value remained stable over time, 100 snapshots were extracted from the attained 
trajectory to ensure the lowest standard error in the free energy estimation and the lowest calculation time. The MM-PBSA.py module ${ }^{35}$ was employed to perform these calculations, keeping all parameters at the default values. In our calculations, the single trajectory approach of MM-GBSA was applied, and the entropic contribution to $\Delta \mathrm{G}$ was omitted. For this reason, our ligand binding free energy values were termed $\left\langle<\Delta \mathrm{G}^{*}\right\rangle>$ throughout the text.

Design of RIm compounds. New MeIm analogs (RIm compounds) were manually constructed by adding or modifying the atoms comprising the ligand moieties in the PCSK9/MeIm complex representing the most populated cluster of conformations. The editing tools available in the Maestro software (Schrödinger, Inc.) were utilized toward this aim. The carboxylic or amino groups, if present in the ligand structures, were considered in their ionized form, for consistency with the expected protonation state at the physiological $\mathrm{pH}$. Then, RIm compounds followed the computational protocols (MD simulations, cluster analysis, and MM-GBSA calculations) as described above.

\section{Synthetic procedures.}

\section{5-(4-Methoxyphenyl)-1-methyl-1H-imidazole (7)}

p-Anisaldehyde ( $1 \mathrm{~g}, 7.3 \mathrm{mmol}$ ) was dissolved in DMF ( $8 \mathrm{~mL}$ ). Methylamine ( $40 \mathrm{wt}$. \% aqueous solution, $1.3 \mathrm{~mL}, 14.6 \mathrm{mmol}$ ) was added and the resulting mixture was kept under stirring for $2 \mathrm{~h}$ at room temperature. Potassium carbonate $(1.5 \mathrm{~g}, 10.9 \mathrm{mmol})$ and tosylmethyl isocyanide $(1.7 \mathrm{~g}, 8.8 \mathrm{mmol})$ were added sequentially, the reaction was stirred for additional $3 \mathrm{~h}$ at $50{ }^{\circ} \mathrm{C}$ and then left overnight at room temperature under stirring. The resulting mixture was partitioned between AcOEt and water. The aqueous phase was extracted with AcOEt (x3) and the organic phase was washed with brine (x5), dried over $\mathrm{Na}_{2} \mathrm{SO}_{4}$ and concentrated under reduced pressure, to give a residue that was purified by trituration in diethyl ether. The product was obtained as a yellowish solid (82\% yield). ${ }^{1} \mathrm{H}$ NMR (300 $\left.\mathrm{MHz}, \mathrm{CDCl}_{3}\right) \delta$ 7.48 (s, 1H), 7.29 (d, $J=8.7 \mathrm{~Hz}, 2 \mathrm{H}), 7.02(\mathrm{~s}, 1 \mathrm{H}), 6.95$ (d, $J=8.7 \mathrm{~Hz}, 2 \mathrm{H}), 3.83$ (s, 3H), 3.61 (s, 3H);

${ }^{13} \mathrm{C} \mathrm{NMR}\left(100 \mathrm{MHz}, \mathrm{CDCl}_{3}\right) \delta 159.4(\mathrm{Cq}), 138.6,133.2(\mathrm{Cq}), 129.9$ (2C), 127.5, $122.2(\mathrm{Cq}), 114.2(2 \mathrm{C})$, 55.3, 32.3. HRMS (ESI) $\mathrm{m} / \mathrm{z}$ : $[\mathrm{M}+\mathrm{H}]^{+}$Calcd for $\mathrm{C}_{11} \mathrm{H}_{13} \mathrm{~N}_{2} \mathrm{O}$ 189.1022; Found 189.1026.

\section{5-(4-Methoxyphenyl)-1-methyl-1H-imidazole-2-carbaldehyde (8)}

To a solution of compound 7 ( $3.5 \mathrm{~g}, 18.6 \mathrm{mmol})$ in dry THF $(37 \mathrm{~mL})$ under nitrogen atmosphere cooled to $-78{ }^{\circ} \mathrm{C}$, a solution of $n$-butyl lithium $(1.6 \mathrm{M}$ in hexane, $17.5 \mathrm{~mL}, 27.9 \mathrm{mmol})$ was added dropwise, and the resulting mixture was kept under stirring for $2 \mathrm{~h}$ at the same temperature. Dimethylformamide (2.9 
$\mathrm{mL}, 37.2 \mathrm{mmol}$ ) was added and the reaction was stirred for $2 \mathrm{~h}$ at room temperature. The resulting mixture was quenched with distilled water and extracted with AcOEt (x2). The organic phase was washed with brine (x4), dried over $\mathrm{Na}_{2} \mathrm{SO}_{4}$, and concentrated under reduced pressure, to give a residue that was purified by $\mathrm{FC}\left(\mathrm{CH}_{2} \mathrm{Cl}_{2} / \mathrm{MeOH}\right.$ 99/1). The purified product was obtained as a yellowish solid (77\% yield). ${ }^{1} \mathrm{H}$ NMR (300 MHz, CDCl 3$) \delta 10.04$ (s, 1H), 7.35 (d, $\left.J=8.3 \mathrm{~Hz}, 2 \mathrm{H}\right), 7.25$ (s, 1H), 7.05 (d, $J=$ $8.3 \mathrm{~Hz}, 2 \mathrm{H}), 3.99$ (s, 3H), 3.87 (s, 3H); ${ }^{13} \mathrm{C}$ NMR (75 MHz, CD $\left.{ }_{3} \mathrm{OD}\right) \delta 163.2,149.5,134.5,132.7$ (2C), 129.6, 122.8, 116.1 (2C), 91.1, 56.3, 33.9. HRMS (ESI) $m / z:[\mathrm{M}+\mathrm{H}]^{+}$Calcd for $\mathrm{C}_{12} \mathrm{H}_{13} \mathrm{~N}_{2} \mathrm{O}_{2}$ 217.0972; Found 217.0978.

\section{3'-Benzyl-5-(4-methoxyphenyl)- 1-methyl-1H,3'H,2,4'-biimidazole (9)}

Aldehyde 8 (300 mg, $1.4 \mathrm{mmol})$ was dissolved in DMF $(1.4 \mathrm{~mL})$ at $0{ }^{\circ} \mathrm{C}$. Benzylamine (180 $\mu \mathrm{L}, 1.7$ mmol) was added and the resulting mixture was kept under stirring for $2 \mathrm{~h}$ at $70{ }^{\circ} \mathrm{C}$ under nitrogen atmosphere. Then, potassium carbonate ( $288 \mathrm{mg}, 1.7 \mathrm{mmol}$ ) and tosylmethyl isocyanide (326 mg, 2.1 mmol) were sequentially added and the reaction was stirred for additional $2 \mathrm{~h}$ at $70^{\circ} \mathrm{C}$. After that, further tosylmethyl isocyanide $\left(326 \mathrm{mg}, 2.1 \mathrm{mmol}\right.$ ) was added. The reaction was left overnight at $70{ }^{\circ} \mathrm{C}$ under stirring. The resulting mixture was partitioned between AcOEt and water. The aqueous phase was extracted with AcOEt (x3) and the organic phase was washed with brine (x5), dried over $\mathrm{Na}_{2} \mathrm{SO}_{4}$, and concentrated under reduced pressure, to give a residue that was purified by chromatography on neutral aluminum oxide (AcOEt/ $\mathrm{MeOH}$ gradient from 97/3 to 92/8). The purified product was obtained as a dark brown foamy solid (48\% yield). ${ }^{1} \mathrm{H}$ NMR (400 MHz, $\left.\mathrm{CDCl}_{3}\right) \delta 7.63(\mathrm{~s}, 1 \mathrm{H}), 7.25-7.13(\mathrm{~m}, 6 \mathrm{H})$, $7.10(\mathrm{~s}, 1 \mathrm{H}), 6.96-6.88(\mathrm{~m}, 4 \mathrm{H}), 5.34(\mathrm{~s}, 2 \mathrm{H}), 3.77(\mathrm{~s}, 3 \mathrm{H}), 3.15$ (s, 3H); ${ }^{13} \mathrm{C} \mathrm{NMR}\left(101 \mathrm{MHz}, \mathrm{CDCl}_{3}\right)$ $\delta$ 160.2, 139.7, 139.0, 137.3, 135.2, 131.4, 130.7 (2C), 129.2 (2C), 128.5, $128.3(2 \mathrm{C}), 127.8,122.9,122.8$, 114.9 (2C), 56.0, 50.2, 32.9. HRMS (ESI) $m / z:[\mathrm{M}+\mathrm{H}]^{+}$Calcd for $\mathrm{C}_{21} \mathrm{H}_{21} \mathrm{~N}_{4} \mathrm{O} 345.1710$; Found 345.1716.

\section{3'-Phenethyl-5-(4-methoxyphenyl)-1-methyl-1H,3'H-2,4'-biimidazole (10)}

Aldehyde 8 (100 mg, $0.5 \mathrm{mmol})$ was dissolved in DMF (0.5 mL). Phenethylamine (70 $\mu \mathrm{L}, 0.6 \mathrm{mmol})$ was added and the resulting mixture was kept under stirring for $2 \mathrm{~h}$ at $70{ }^{\circ} \mathrm{C}$ under nitrogen atmosphere. Potassium carbonate $(95 \mathrm{mg}, 0.7 \mathrm{mmol}$ ) and tosylmethyl isocyanide $(107 \mathrm{mg}, 0.6 \mathrm{mmol}$ ) were sequentially added and the reaction was stirred for additional $2 \mathrm{~h}$ at $70^{\circ} \mathrm{C}$ before adding other tosylmethyl isocyanide ( $107 \mathrm{mg}, 0.6 \mathrm{mmol})$. Then the reaction was left overnight at $70{ }^{\circ} \mathrm{C}$ under stirring. The resulting mixture was then partitioned between AcOEt and water. The aqueous phase was extracted with AcOEt (x3) and the organic phase was washed with brine (x5), dried over $\mathrm{Na}_{2} \mathrm{SO}_{4}$ and concentrated under 
reduced pressure, to give a residue that was purified by chromatography on neutral alumina oxide (AcOEt/ MeOH gradient from 97/3 to 92/8). The purified product was obtained as a dark brown foamy solid (45\% yield). ${ }^{1} \mathrm{H}$ NMR (400 $\left.\mathrm{MHz} \mathrm{CDCl}_{3}\right) \delta 7.45(\mathrm{~s}, 1 \mathrm{H}), 7.35(\mathrm{~d}, J=8.6 \mathrm{~Hz}, 2 \mathrm{H}), 7.22-7.07(\mathrm{~m}$, $5 \mathrm{H}), 6.99(\mathrm{~m}, 4 \mathrm{H}), 4.63(\mathrm{t}, J=6.9 \mathrm{~Hz}, 2 \mathrm{H}), 3.86(\mathrm{~s}, 3 \mathrm{H}), 3.43(\mathrm{~s}, 3 \mathrm{H}), 2.99(\mathrm{t}, J=6.9 \mathrm{~Hz}, 2 \mathrm{H}) ;{ }^{13} \mathrm{C} \mathrm{NMR}$ $\left(100 \mathrm{MHz} \mathrm{CDCl}_{3}\right) \delta 160.3,139.7,138.4,135.1,131.6,130.8$ (2C), 130.6, 129.4 (2C), 129.1 (2C), 127.8, 127.2, 123.0 (2C), 115.0 (2C), 56.0, 47.7, 38.6, 33.6. HMRS (ESI) $m / z:[\mathrm{M}+\mathrm{H}]^{+}$Calcd for $\mathrm{C}_{22} \mathrm{H}_{23} \mathrm{~N}_{4} \mathrm{O}$ 359.1866; Found 359.1861.

\section{3'-Benzyl-5-(4-methoxyphenyl)- 1-methyl-1H,3' H-[2,4' biimidazole]-2'-carbaldehyde (11)}

To a solution of compound $9(530 \mathrm{mg}, 1.5 \mathrm{mmol})$ and TMEDA (1.4 mL, $9 \mathrm{mmol})$ in dry THF (15 mL) under nitrogen atmosphere cooled to $-78{ }^{\circ} \mathrm{C}$, a solution of $n$-butyl lithium $(1.6 \mathrm{M}$ in hexane, $2.8 \mathrm{~mL}, 4.5$ mmol) was added dropwise. The resulting mixture was kept under stirring for $2 \mathrm{~h}$, allowing the temperature to reach $-30{ }^{\circ} \mathrm{C}$. The temperature was brought at $-78{ }^{\circ} \mathrm{C}$ again and dimethylformamide $(1$ $\mathrm{mL}, 12.8 \mathrm{mmol}$ ) was added. The reaction was stirred for additional $2 \mathrm{~h}$ at room temperature. The resulting mixture was then quenched with distilled water and extracted with AcOEt (x2). The organic phase was washed with brine $(x 4)$, dried over $\mathrm{Na}_{2} \mathrm{SO}_{4}$ and concentrated under reduced pressure. The product was purified by $\mathrm{FC}$ (AcOEt/ $\mathrm{CH}_{2} \mathrm{Cl}_{2}$ 7/3). The purified product was obtained as a brown foamy solid (43\% yield). ${ }^{1} \mathrm{H}$ NMR $\left(300 \mathrm{MHz}, \mathrm{CDCl}_{3}\right) \delta 9.95(\mathrm{~s}, 1 \mathrm{H}), 7.53(\mathrm{~s}, 1 \mathrm{H}), 7.29-7.15(\mathrm{~m}, 6 \mathrm{H}), 6.99(\mathrm{~d}, J=8.8 \mathrm{~Hz}$, $2 \mathrm{H}), 6.92-6.85(\mathrm{~m}, 2 \mathrm{H}), 6.06(\mathrm{~s}, 2 \mathrm{H}), 3.85(\mathrm{~s}, 3 \mathrm{H}), 3.06(\mathrm{~s}, 3 \mathrm{H}) ;{ }^{13} \mathrm{C} \mathrm{NMR}\left(75 \mathrm{MHz}, \mathrm{CDCl}_{3}\right) \delta 182.6$, 160.6, 144.8, 136.5, 135.8, 135.2, 131.3, 130.5, 130.4 (2C), 128.6 (2C), 128.0, 127.9, 127.5 (2C), 119.8, 114.6 (2C), 55.4, 48.6, 32.3. HRMS (ESI) $m / z$ : $[\mathrm{M}+\mathrm{H}]^{+}$Calcd for $\mathrm{C}_{22} \mathrm{H}_{21} \mathrm{~N}_{4} \mathrm{O}_{2}$ 373.1659; Found 373.1651 .

\section{3'-Phenetyl-5-(4-methoxyphenyl)- 1-methyl-1H,3'H-[2,4' biimidazole]-2'-carbaldehyde (12)}

To a solution of compound $10(530 \mathrm{mg}, 1.5 \mathrm{mmol})$ and TMEDA (1.3 mL, $9 \mathrm{mmol})$ in dry THF (15 mL) under nitrogen atmosphere cooled to $-78^{\circ} \mathrm{C}$, a solution of $n$-butyl lithium $(1.6 \mathrm{M}$ in hexane, $2.8 \mathrm{~mL}, 4.5$ mmol) was added dropwise. The resulting mixture was kept under stirring for $2 \mathrm{~h}$, allowing the temperature to reach $-30{ }^{\circ} \mathrm{C}$. The temperature was brought at $-78{ }^{\circ} \mathrm{C}$ again and dimethylformamide $(1$ $\mathrm{mL}, 12.8 \mathrm{mmol}$ ) was added. The reaction was stirred for additional $2 \mathrm{~h}$ at room temperature. The resulting mixture was then quenched with distilled water and extracted with AcOEt (x2). The organic phase was washed with brine (x4), dried over $\mathrm{Na}_{2} \mathrm{SO}_{4}$ and concentrated under reduced pressure. The product was purified by flash chromatography (AcOEt/ $\mathrm{CH}_{2} \mathrm{Cl}_{2}$ gradient from 6/4 to 9/1) to give a brownish foamy 
solid (77\% yield). ${ }^{1} \mathrm{H}$ NMR (400 MHz, $\left.\mathrm{CDCl}_{3}\right) \delta 9.92(\mathrm{~s}, 1 \mathrm{H}), 7.37(\mathrm{~s}, 1 \mathrm{H}), 7.34(\mathrm{~d}, J=8.7 \mathrm{~Hz}, 2 \mathrm{H})$, $7.21(\mathrm{~s}, 1 \mathrm{H}), 7.15-7.07(\mathrm{~m}, 3 \mathrm{H}), 7.04(\mathrm{~d}, J=8.7 \mathrm{~Hz}, 2 \mathrm{H}), 6.95(\mathrm{~d}, \mathrm{br}, J=7.8 \mathrm{~Hz}, 2 \mathrm{H}), 5.16(\mathrm{t}, J=6.9$ $\mathrm{Hz}, 2 \mathrm{H}), 3.90(\mathrm{~s}, 3 \mathrm{H}), 3.25$ (s, 3H), $3.08(\mathrm{t}, J=6.9 \mathrm{~Hz}, 2 \mathrm{H}) ;{ }^{13} \mathrm{C} \mathrm{NMR}\left(100 \mathrm{MHz}, \mathrm{CDCl}_{3}\right) \delta 182.6,160.5$, 144.9, 138.4, 137.7, 136.0, 132.6, 130.9 (2C), 129.6 (2C), 128.8 (2C), 128.5, 127.0, 122.4 (2C), 115.1 (2C), 56.1, 47.2, 37.8, 33.5. HMRS (ESI): $m / z$ : $[\mathrm{M}+\mathrm{H}]^{+}$Calcd for $\mathrm{C}_{23} \mathrm{H}_{23} \mathrm{~N}_{4} \mathrm{O}_{2}$ 387.1816; Found 387.1821.

\section{tert-Butyl (5-(3'-benzyl-5-(4-methoxyphenyl)-1-methyl-1H,3'H,3' 'H-[2,4':2',4' '-terimidazol]-3'"-}

\section{yl)pentyl)(methyl)carbamate (14)}

Aldehyde 11 (40 mg, $0.11 \mathrm{mmol})$ was dissolved in DMF (0.11 mL). Primary amine 13 (29 mg, 0.13 mmol) was added and the resulting mixture was kept under stirring for $2 \mathrm{~h}$ at $70{ }^{\circ} \mathrm{C}$ under nitrogen atmosphere. Potassium carbonate $(23 \mathrm{mg}, 0.16 \mathrm{mmol})$ and tosylmethyl isocyanide $(26 \mathrm{mg}, 0.13 \mathrm{mmol})$ were sequentially added and the reaction was stirred for additional $2 \mathrm{~h}$ at $70{ }^{\circ} \mathrm{C}$. After that, further tosylmethyl isocyanide $(26 \mathrm{mg}, 0.13 \mathrm{mmol})$ was added. The reaction was left overnight at $70{ }^{\circ} \mathrm{C}$ under stirring. The resulting mixture was partitioned between AcOEt and water. The aqueous phase was extracted with AcOEt (x3) and the organic phase was washed with brine (x5), dried over $\mathrm{Na}_{2} \mathrm{SO}_{4}$ and concentrated under reduced pressure, to give a residue that was purified by chromatography on neutral aluminum oxide (AcOEt/ MeOH gradient from 97/3 to 92/8). The purified product was obtained as a brown foamy solid (45\% yield). ${ }^{1} \mathrm{H} \mathrm{NMR}\left(400 \mathrm{MHz}, \mathrm{CDCl}_{3}, 4: 1\right.$ rotameric mixture) $\delta 7.62(\mathrm{~s}, \mathrm{br}, 1 \mathrm{H})$, $7.42(\mathrm{~s}, 1 \mathrm{H}), 7.22(\mathrm{~d}, J=8.7 \mathrm{~Hz}, 2 \mathrm{H}), 7.20(\mathrm{~s}, \mathrm{br}, 1 \mathrm{H}), 7.20-7.16(\mathrm{~m}, 3 \mathrm{H}), 7.14(\mathrm{~s}, 1 \mathrm{H}), 6.98(\mathrm{~d}, J=8.7$ $\mathrm{Hz}, 2 \mathrm{H}), 6.85-6.78(\mathrm{~m}, 2 \mathrm{H}), 5.56(\mathrm{~s}, 2 \mathrm{H}), 4.14(\mathrm{t}, \mathrm{br}, J=7.3 \mathrm{~Hz}, 1.6 \mathrm{H}), 3.94$ (t, br, $J=7.3 \mathrm{~Hz}, 0.4 \mathrm{H})$, $3.86(\mathrm{~s}, 3 \mathrm{H}), 3.29(\mathrm{~s}, 3 \mathrm{H}), 3.18(\mathrm{~m}, \mathrm{br}, 2 \mathrm{H}), 2.82$ (s, br, 3H), 1.82 (quint, br, $J=7.4 \mathrm{~Hz}, 0.4 \mathrm{H}), 1.67$ (quint, br, $J=7.4 \mathrm{~Hz}, 1.6 \mathrm{H}$ ), $1.57-1.46(\mathrm{~m}, 2 \mathrm{H}), 1.46(\mathrm{~s}, 9 \mathrm{H}), 1.26$ (quint, br, $J=7.3 \mathrm{~Hz}, 2 \mathrm{H}$ ); ${ }^{13} \mathrm{C}$ NMR (101 MHz, $\mathrm{CDCl}_{3}, 4: 1$ rotameric mixture) $\delta 160.3,156.4,140.8,139.8,139.0,137.9,135.3,131.5$, 131.4, 130.8 (2C), 129.2 (2C), 128.2, 128.1, 127.3 (2C), 124.2, 122.8, 122.1, 114.9 (2C), 79.9, 56.0, 49.2, 49.2 (br), 47.7 and 46.5 (1C), 34.8, 33.0, 31.5 and 31.3 (1C), 29.2 (3C), 28.0 and 27.8 (1C, br), 24.4. HRMS (ESI) $m / z:[\mathrm{M}+\mathrm{H}]^{+}$Calcd for $\mathrm{C}_{35} \mathrm{H}_{44} \mathrm{~N}_{7} \mathrm{O}_{3}$ 610.3500, Found 610.3508.

tert-Butyl (5-(3'-phenetyl-5-(4-methoxyphenyl)-1-methyl-1H,3'H,3' 'H-[2,4' :2',4' '-terimidazol]-3'"yl)pentyl)(methyl)carbamate (15)

Aldehyde 12 (90 mg, $0.25 \mathrm{mmol}$ ) was dissolved in DMF (0.25 mL). Primary amine 13 (65 mg, $0.3 \mathrm{mmol})$ was added and the resulting mixture was kept under stirring for $2 \mathrm{~h}$ at $70{ }^{\circ} \mathrm{C}$ under nitrogen atmosphere. 
Potassium carbonate $(52 \mathrm{mg}, 0.37 \mathrm{mmol})$ and tosylmethyl isocyanide (59 $\mathrm{mg}, 0.3 \mathrm{mmol})$ were sequentially added and the reaction was stirred for additional 2 hours at $70{ }^{\circ} \mathrm{C}$. After that, further tosylmethyl isocyanide $(59 \mathrm{mg}, 0.3 \mathrm{mmol})$ was added. The reaction was left overnight at $70{ }^{\circ} \mathrm{C}$ under stirring. The resulting mixture was then partitioned between AcOEt and water. The aqueous phase was extracted with AcOEt (x3) and the organic phase was washed with brine (x5), dried over $\mathrm{Na}_{2} \mathrm{SO}_{4}$ and concentrated under reduced pressure, to give a residue that was purified by chromatography on neutral alumina oxide (AcOEt/ MeOH gradient from 97/3 to 92/8). The purified product was obtained as a brown foamy solid (40\% yield). ${ }^{1} \mathrm{H}$ NMR $\left(400 \mathrm{MHz}, \mathrm{CDCl}_{3}\right) \delta 7.60(\mathrm{~s}, 1 \mathrm{H}), 7.34(\mathrm{~d}, J=8.3 \mathrm{~Hz}, 2 \mathrm{H}), 7.31$ (s, 1H), $7.21(\mathrm{~s}, 1 \mathrm{H}), 7.17(\mathrm{~s}, 1 \mathrm{H}), 7.15-7.08(\mathrm{~m}, 3 \mathrm{H}), 7.00(\mathrm{~d}, J=8.4 \mathrm{~Hz}, 2 \mathrm{H}), 6.89(\mathrm{~d}, J=7.7 \mathrm{~Hz}, 2 \mathrm{H})$, $4.72(\mathrm{t}, \mathrm{br}, J=6.8 \mathrm{~Hz}, 2 \mathrm{H}), 4.08(\mathrm{t}, \mathrm{br}, J=7.0 \mathrm{~Hz}, 2 \mathrm{H}), 3.85(\mathrm{~s}, 3 \mathrm{H}), 3.46(\mathrm{~s}, 3 \mathrm{H}), 3.15(\mathrm{~m}, \mathrm{br}, 2 \mathrm{H}), 2.83$ (t, br, $J=7.0 \mathrm{~Hz}, 2 \mathrm{H}), 2.78$ (s, 3H), 1.70 (quint, br, $J=7.2 \mathrm{~Hz}, 2 \mathrm{H}), 1.47$ (m, br, 2H), 1.42 (s, 9H), 1.24 (quint, br, $J=7.2 \mathrm{~Hz}, 2 \mathrm{H}) ;{ }^{13} \mathrm{C} \mathrm{NMR}\left(100 \mathrm{MHz}, \mathrm{CDCl}_{3}\right), \delta 160.3,156.4,140.2,139.7,139.5,138.0$, 135.3, 131.1 (2C), 130.8 (2C), 129.4 (2C), 129.0 (2C), 127.9, 127.2, 124.0, 122.8, 122.2, 115.0 (2C), 79.9, 56.0, 49.2, 46.8, 46.6, 38.0, 34.8, 33.7, 31.3, 29.1 (3C), 27.9, 24.4. HMRS (ESI) $\mathrm{m} / z:[\mathrm{M}+\mathrm{H}]^{+} \mathrm{Calcd}$ for $\mathrm{C}_{36} \mathrm{H}_{46} \mathrm{~N}_{7} \mathrm{O}_{3} 624.3657$; Found 624.3648.

\section{1-(3'-Benzyl-5-(4-methoxyphenyl)-1-methyl-1H,3'H,3' 'H-[2,4' :2',4' '-terimidazol]-3' '-yl)-N- methylmethanamine (RIm13)}

To a solution of compound $14(80 \mathrm{mg})$ in $\mathrm{AcOEt}(0.5 \mathrm{~mL})$ under nitrogen atmosphere, $\mathrm{HCl} 4 \mathrm{~N}$ in $\mathrm{AcOEt}$ $(0.5 \mathrm{~mL})$ was added at $0{ }^{\circ} \mathrm{C}$. The reaction was allowed to room temperature and left under stirring overnight. The reaction mixture was filtered on a Hirsch funnel and the solid was partitioned between $\mathrm{NaHCO}_{3}$ sat aq solution and $\mathrm{CH}_{2} \mathrm{Cl}_{2}$. The aqueous phase was extracted with $\mathrm{CH}_{2} \mathrm{Cl}_{2}$ (x3). The collected organic phase was dried over $\mathrm{Na}_{2} \mathrm{SO}_{4}$ and concentrated under reduced pressure. The product was obtained as a brown foamy solid (quantitative yield). ${ }^{1} \mathrm{H}$ NMR $\left(400 \mathrm{MHz}, \mathrm{CDCl}_{3}\right) \delta 7.62$ (s, br, $\left.1 \mathrm{H}\right), 7.42$ $(\mathrm{s}, 1 \mathrm{H}), 7.31-7.16(\mathrm{~m}, 6 \mathrm{H}), 7.14(\mathrm{~s}, 1 \mathrm{H}), 6.99(\mathrm{~d}, J=8.6 \mathrm{~Hz}, 2 \mathrm{H}), 6.85-6.75(\mathrm{~m}, 2 \mathrm{H}), 5.54(\mathrm{~s}, 2 \mathrm{H})$, $4.13(\mathrm{t}, \mathrm{br}, J=7.2 \mathrm{~Hz}, 2 \mathrm{H}), 3.86(\mathrm{~s}, 3 \mathrm{H}), 3.85(\mathrm{~m}, \mathrm{br}, 1 \mathrm{H}), 3.27(\mathrm{~s}, 3 \mathrm{H}), 2.55$ (t, br, $J=6.8 \mathrm{~Hz}, 2 \mathrm{H}), 2.43$ (s, br, 3H), 1.65 (quint, br, $J=7.2 \mathrm{~Hz}, 2 \mathrm{H}$ ), 1.46 (quint, br, $J=7.1 \mathrm{~Hz}, 2 \mathrm{H}$ ), 1.29 (quint, br, $J=7.2 \mathrm{~Hz}$, $2 \mathrm{H}) ;{ }^{13} \mathrm{C}$ NMR (101 MHz, $\left.\mathrm{CDCl}_{3}\right) \delta 159.7,140.1,139.2,138.3,137.3,134.6,130.8$ (2C), 130.1 (2C), 128.6 (2C), 127.6, 127.5, 126.7 (2C), 123.4, 122.1, 121.5, 114.3 (2C), 55.4, 51.7, 48.5, 45.8, 36.4, 32.3, 30.8, 29.1, 24.3. HRMS (ESI) $m / z:[\mathrm{M}+\mathrm{H}]^{+}$Calcd for $\mathrm{C}_{30} \mathrm{H}_{36} \mathrm{~N}_{7} \mathrm{O}$ 510.2976; Found 510.2988. Anal. Calcd for $\mathrm{C}_{30} \mathrm{H}_{35} \mathrm{~N}_{7} \mathrm{O}$ : C, 70.70; H, 6.92; N, 19.24; Found: C, 70.48; H, 7.01; N, 19.32. 


\section{1-(3'-Phenetyl-5-(4-methoxyphenyl)-1-methyl-1H,3'H,3' 'H-[2,4' :2',4' '-terimidazol]-3"'-yl)-N-}

\section{methylmethanamine (RIm14)}

To a solution of compound $15(80 \mathrm{mg})$ in $\mathrm{AcOEt}(0.5 \mathrm{~mL})$ under nitrogen atmosphere, $\mathrm{HCl} 4 \mathrm{~N}$ in AcOEt $(0.5 \mathrm{~mL})$ was added at $0{ }^{\circ} \mathrm{C}$. The reaction was allowed to room temperature and left under stirring overnight. The reaction mixture was filtered on a Hirsch funnel and the solid was partitioned between $\mathrm{NaHCO}_{3}$ sat aq solution and $\mathrm{CH}_{2} \mathrm{Cl}_{2}$. The aqueous phase was extracted with $\mathrm{CH}_{2} \mathrm{Cl}_{2}$ (x3). The collected organic phase was dried over $\mathrm{Na}_{2} \mathrm{SO}_{4}$ and concentrated under reduced pressure. The final product was obtained as a dark brown foamy solid (quantitative yield). ${ }^{1} \mathrm{H} \mathrm{NMR}\left(400 \mathrm{MHz}, \mathrm{CDCl}_{3}\right) \delta 7.63(\mathrm{~s}, 1 \mathrm{H})$, $7.37(\mathrm{~d}, J=8.1 \mathrm{~Hz}, 2 \mathrm{H}), 7.34(\mathrm{~s}, 1 \mathrm{H}), 7.23(\mathrm{~s}, 1 \mathrm{H}), 7.20(\mathrm{~s}, 1 \mathrm{H}), 7.18-7.10(\mathrm{~m}, 3 \mathrm{H}), 7.02(\mathrm{~d}, J=8.1 \mathrm{~Hz}$, $2 \mathrm{H}), 6.93(\mathrm{~d}, J=8.1 \mathrm{~Hz}, 2 \mathrm{H}), 4.73(\mathrm{t}, \mathrm{br}, J=6.8 \mathrm{~Hz}, 2 \mathrm{H}), 4.11(\mathrm{t}, \mathrm{br}, J=7.0 \mathrm{~Hz}, 2 \mathrm{H}), 3.88(\mathrm{~s}, 3 \mathrm{H}), 3.49$ (s, 3H), 2.84 (t, br, $J=6.8 \mathrm{~Hz}, 2 \mathrm{H}$ ), 2.53 (t, br, $J=7.0 \mathrm{~Hz}, 2 \mathrm{H}$ ), 2.40 (s, 3H), 1.71 (quint, br, $J=7.3 \mathrm{~Hz}$, 2H), 1.46 (quint, br, $J=7.4 \mathrm{~Hz}, 2 \mathrm{H}$ ), 1.38 (m, br, 1H), 1.31 (quint, br, $J=7.3 \mathrm{~Hz}, 2 \mathrm{H}$ ); ${ }^{13} \mathrm{C}$ NMR $(100$ $\left.\mathrm{MHz}, \mathrm{CDCl}_{3}\right), \delta$ 160.3, 140.2, 139.7, 139.5, 138.1, 135.3, 131.2, 131.0, 130.8 (2C), 129.4 (2C), 129.0 (2C), 128.0, 127.2, 124.0, 122.9, 122.3, 115.0 (2C), 56.1, 52.3, 46.9, 46.6, 38.1, 37.0, 33.7, 31.5, 29.8, 24.9. HMRS (ESI): $\mathrm{m} / z[\mathrm{M}+\mathrm{H}]^{+}$Calcd for $\mathrm{C}_{31} \mathrm{H}_{38} \mathrm{~N}_{7} \mathrm{O}$ 524.3132; Found 524.3138. Anal. Calcd for $\mathrm{C}_{31} \mathrm{H}_{37} \mathrm{~N}_{7} \mathrm{O}$ : C, 71.10; H, 7.12; N, 18.72; Found: C, 71.28; H, 7.19; N, 18.89.

Biological assay materials. The HepG2 cell line was bought from ATCC (HB-8065, ATCC from LGC Standards, Milan, Italy). Dulbecco's modified Eagle's medium, (DMEM), 96-Well plates, L-glutamine, fetal bovine serum (FBS), phosphate buffered saline (PBS), penicillin/streptomycin, and chemiluminescent reagent were purchased from Euroclone (Milan, Italy). Janus green were bought from Abcam (Cambridge, UK), while the antibodies against anti-rabbit Ig-HRP, was purchased from Santa Cruz Biotechnology Inc. (Santa Cruz, CA, US). Antibody against LDLR and TMB substrate were obtained from Pierce (Rockford, IL, US). LDL-DyLight ${ }^{\mathrm{TM}} 550$ (Cayman Chemical Company, Ann Arbor, MI, US). Synthetic peptides were synthesized by the company GenScript (Piscataway, NJ, USA) at $>95 \%$ purity.

PCSK9-LDLR binding Assay. Compound RIm13, RIm14, compound 9, and peptide P5 (0.01 $\mu \mathrm{M}-$ $100.0 \mu \mathrm{M}$ ) were tested using the in vitro PCSK9-LDLR binding assay (CycLex Co., Nagano, Japan), following the manufacture instructions. The absorbance at $450 \mathrm{~nm}$ was measured using the Synergy $\mathrm{H} 1$ fluorescent plate reader (Biotek, Bad Friedrichshall, Germany). In particular, for the in vitro screening of the synthetic PCSK9-LDLR inhibitors, at different concentrations, were added to the appropriate 
amount of His-tagged PCSK9 in the wells that had been coated with recombinant LDLR-AB domain, followed by evaluation of inhibitory effect on PCSK9-LDLR interaction by measuring the amount of His-tagged PCSK9 on the wells which is correlated to the absorbance signals at $450 \mathrm{~nm}$, which were measured using the Synergy H1 fluorescent plate reader (Biotek, Bad Friedrichshall, Germany).

Cell culture conditions and ICW assay. The HepG2 cell line was cultured in DMEM high glucose with stable L-glutamine supplemented with $10 \%$ FBS, $100 \mathrm{U} / \mathrm{mL}$ penicillin, $100.0 \mu \mathrm{g} / \mathrm{mL}$ streptomycin and incubated at $37^{\circ} \mathrm{C}$ under $5 \% \mathrm{CO}_{2}$ atmosphere. HepG2 cells were used for no more than 20 passages after thawing, because the increase of the number of passages may change the cell characteristics and impair assay results. A total of $3.0 \times 10^{4} \mathrm{HepG} 2$ cells/well were seeded in 96-well plates, respectively. The following day, cells were washed with PBS and then starved overnight $(\mathrm{O} / \mathrm{N})$ in DMEM without FBS. HepG2 cells were treated with $4.0 \mu \mathrm{g} / \mathrm{mL}$ PCSK9 (K9) and $4.0 \mu \mathrm{g} / \mathrm{mL}$ K9 + RIm13 compound (0.1 $10.0 \mu \mathrm{M})$, compound $9(10.0 \mu \mathrm{M})$, peptide P5 $(1.0 \mu \mathrm{M})$, and vehicle $\left(\mathrm{H}_{2} \mathrm{O}\right)$ for $2 \mathrm{~h}$ at $37{ }^{\circ} \mathrm{C}$ under $5 \%$ $\mathrm{CO}_{2}$ atmosphere. Treated HepG2 cells were fixed in $4 \%$ paraformaldehyde for 20 min at room temperature (RT). Cells were washed 5 times with $100.0 \mu \mathrm{L}$ of PBS/well (each wash was for 5 min at RT) and the endogenous peroxides activity was quenched adding $3 \% \mathrm{H}_{2} \mathrm{O}_{2}$ in PBS for 20 min at RT. Non-specific sites were blocked with $100.0 \mu \mathrm{L} /$ well of $5 \% \mathrm{BSA}$ in PBS for $1.5 \mathrm{~h}$ at RT. LDLR primary antibody solution (1:3000 in 5\% BSA in PBS, $25 \mu \mathrm{L} /$ well) was incubated $\mathrm{O} / \mathrm{N}$ at $4{ }^{\circ} \mathrm{C}$. Subsequently, the primary antibody solution was discarded and each sample was washed 5 times with $100.0 \mu \mathrm{L} /$ well of PBS (each wash was for 5 min at RT). Goat anti-rabbit Ig-HRP secondary antibody solution (1:6000 in 5\% BSA in PBS, $50.0 \mu \mathrm{L} /$ well) was added and incubated $1 \mathrm{~h}$ at RT. The secondary antibody solution was washed 5 times with $100.0 \mu \mathrm{L} /$ well of PBS (each wash for 5 min at RT). Freshly prepared TMB substrate $(100.0 \mu \mathrm{L} /$ well) was added and the plate was incubated at RT until desired colour was developed. The reaction was then stopped with $2 \mathrm{M} \mathrm{H}_{2} \mathrm{SO}_{4}$ and the absorbance at $450 \mathrm{~nm}$ was measured using the Synergy H1 fluorescent plate reader from Biotek. Cells were stained by adding 1 x Janus green stain, incubating for $5 \mathrm{~min}$ at RT. The dye was removed and the sample washed 5 times with water. Afterward $0.1 \mathrm{~mL} 0.5 \mathrm{M} \mathrm{HCl}$ per well were added and incubated for $10 \mathrm{~min}$. After $10 \mathrm{sec}$ shaking, the OD at $595 \mathrm{~nm}$ was measured using the Synergy H1 fluorescent plate reader from Biotek.

Fluorescent LDL uptake cell based assay. HepG2 cells (3.0 x 10\%/well) were seeded in black 96-well plates and kept in complete growth medium for $2 \mathrm{~d}$ before treatment. The third day, they were treated with $4.0 \mu \mathrm{g} / \mathrm{mL} \mathrm{K9}$ and $4.0 \mu \mathrm{g} / \mathrm{mL} \mathrm{K} 9+\mathbf{R I m 1 3}$ compound (0.1-10.0 $\mu \mathrm{M})$, compound $9(10.0 \mu \mathrm{M})$, 
peptide P5 $(1.0 \mu \mathrm{M})$, and, and vehicle $\left(\mathrm{H}_{2} \mathrm{O}\right)$ for $2 \mathrm{~h}$ with at $37^{\circ} \mathrm{C}$ under $5 \% \mathrm{CO}_{2}$ atmosphere. At the end of the treatments, the culture medium was replaced with $50.0 \mu \mathrm{l} /$ well LDL-DyLight ${ }^{\mathrm{TM}} 550$ working solution (Cayman Chemical Company, Ann Arbor, MI, US). The cells were additionally incubated for 2 $\mathrm{h}$ at $37^{\circ} \mathrm{C}$ and then the culture medium was aspirated and replaced with PBS (100.0 $\mu \mathrm{l} /$ well). The degree of LDL uptake was measured using the Synergy H1 fluorescent plate reader from Biotek (excitation and emission wavelengths 540 and $570 \mathrm{~nm}$, respectively).

Statistical analysis of biological assays. Data are presented as mean \pm s.d. using GraphPad Prism 6 (GraphPad, La Jolla, CA, USA). Statistical analyses were carried out by $t$ student test and ANOVA. Pvalues $<0.05$ were considered to be significant.

\section{ASSOCIATED CONTENT}

\section{Supporting Information}

"Supporting Information.pdf" contains Figures S1-S3, Scheme S1, Tables S1-S3, and NMR spectra. "Molecular Formula Strings" can be found in the file MFS.csv.

\section{AUTHOR INFORMATION}

Corresponding Author. Alessandra Silvani and Giovanni Grazioso equally contributed to this work. Email: alessandra.silvani@unimi.it (A.S.),giovanni.grazioso@unimi.it(G.G.)

Author Contributions. The manuscript was written through contributions of all authors. All authors have given approval to the final version of the manuscript.

\section{Notes}

The authors declare no competing financial interests.

\section{ACKNOWLEDGMENTS}

GG thanks Prof. Stefano Moro and Dr. Mattia Sturlese for the availability of the suMD algorithm. We acknowledge the CINECA and the Regione Lombardia award under the LISA initiative, for the availability of high performance computing resources and support. GG gratefully acknowledge the support of "NVIDIA Corporation" with the donation of the Titan Xp GPU: it was utilized for the majority of the calculations here reported. 


\section{ABBREVIATIONS}

CVD, cardio-vascular disease; HRP, horseradish peroxidase; mAbs, monoclonal antibodies; MD, molecular dynamics; MM-GBSA, Molecular Mechanics-Generalized Born Surface Area; suMD, supervised Molecular Dynamics; LDL-C, low-density lipoprotein-cholesterol; LDLR, low-density lipoprotein receptors; O/N, overnight; PCSK9, Proprotein Convertase Subtilisin/Kexin-9; PPI, proteinprotein interaction; DMEM, Dulbecco's modified Eagle's medium; FBS, fetal bovine serum; PBS, phosphate buffered saline; RT, room temperature; TMB, 3,3',5,5'-tetrametilbenzidina.

\section{REFERENCES}

1. Austin, M. A.; Hutter, C. M.; Zimmern, R. L.; Humphries, S. E. Familial Hypercholesterolemia and Coronary Heart Disease: a Huge Association Review. Am. J. Epidemiol. 2004, 160, 421-429.

2. Civeira, F. Guidelines for the Diagnosis and Management of Heterozygous Familial Hypercholesterolemia. Atherosclerosis 2004, 173, 55-68.

3. Seidah, N. G. PCSK9 as a Therapeutic Target of Dyslipidemia. Expert Opin. Ther. Targets 2009, 13, 1928

4. Zaid, A.; Roubtsova, A.; Essalmani, R.; Marcinkiewicz, J.; Chamberland, A.; Hamelin, J.; Tremblay, M.; Jacques, H.; Jin, W.; Davignon, J.; Seidah, N. G.; Prat, A. Proprotein Convertase Subtilisin/kexin Type 9 (PCSK9): Hepatocyte-specific Low-density Lipoprotein Receptor Degradation and Critical Role in Mouse Liver Regeneration. Hepatology 2008, 48, 646-654.

5. Zhang, D. W.; Lagace, T. A.; Garuti, R.; Zhao, Z.; McDonald, M.; Horton, J. D.; Cohen, J. C.; Hobbs, H. H. Binding of Proprotein Convertase Subtilisin/kexin Type 9 to Epidermal Growth Factor-like repeat a of Low Density Lipoprotein Receptor Decreases Receptor Recycling and Increases Degradation. J. Biol. Chem. 2007, 282, 18602-18612.

6. $\quad$ Grefhorst, A.; McNutt, M. C.; Lagace, T. A.; Horton, J. D. Plasma PCSK9 Preferentially Reduces Liver LDL Receptors in Mice. J. Lipid Res. 2008, 49, 1303-1311.

7. Lagace, T. A.; Curtis, D. E.; Garuti, R.; McNutt, M. C.; Park, S. W.; Prather, H. B. Secreted PCSK9 Decreases the Number of LDL Receptors in Hepatocytes and in Livers of Parabiotic Mice. J. Clin. Invest. 2006, 116, 2995-3005.

8. Giugliano, R. P.; Pedersen, T. R.; Park, J. G.; De Ferrari, G. M.; Gaciong, Z. A.; Ceska, R.; Toth, K.; Gouni-Berthold, I.; Lopez-Miranda, J.; Schiele, F.; Mach, F.; Ott, B. R.; Kanevsky, E.; Pineda, A. L.; Somaratne, R.; Wasserman, S. M.; Keech, A. C.; Sever, P. S.; Sabatine, M. S. Clinical Efficacy and Safety of Achieving very Low LDL-cholesterol Concentrations with the PCSK9 Inhibitor Evolocumab: a Prespecified Secondary Analysis of the FOURIER Trial. Lancet 2017, 390, 1962-1971.

9. Bottomley, M. J.; Cirillo, A.; Orsatti, L.; Ruggeri, L.; Fisher, T. S.; Santoro, J. C.; Cummings, R. T.; Cubbon, R. M.; Lo Surdo, P.; Calzetta, A.; Noto, A.; Baysarowich, J.; Mattu, M.; Talamo, F.; De Francesco, R.; Sparrow, C. P.; Sitlani, A.; Carfi, A. Structural and Biochemical Characterization of the Wild Type PCSK9EGF(AB) Complex and Natural Familial Hypercholesterolemia Mutants. J. Biol. Chem. 2009, 284, 1313-1323.

10. Stucchi, M.; Grazioso, G.; Lammi, C.; Manara, S.; Zanoni, C.; Arnoldi, A.; Lesma, G.; Silvani, A. Disrupting the PCSK9/LDLR Protein-Protein Interaction by an Imidazole-based Minimalist Peptidomimetic. Org. Biomol. Chem. 2016, 14, 9736-9740. 
11. Stucchi, M.; Cairati, S.; Cetin-Atalay, R.; Christodoulou, M. S.; Grazioso, G.; Pescitelli, G.; Silvani, A.; Yildirim, D. C.; Lesma, G. Application of the Ugi Reaction with Multiple Amino Acid-derived Components: Synthesis and Conformational Evaluation of Piperazine-based Minimalist Peptidomimetics. Org. Biomol. Chem. 2015, 13, 4993-5005.

12. Taechalertpaisarn, J.; Zhao, B.; Liang, X.; Burgess, K. Small Molecule Inhibitors of the PCSK9.LDLR Interaction. J. Am. Chem. Soc. 2018, 140, 3242-3249.

13. Pettersen, D.; Fjellström, O. Small Molecule Modulators of PCSK9 - A Literature and Patent Overview. Bioorg. Med. Chem. Lett. 2018, 28, 1155-1160.

14. Xu, S.; Luo, S.; Zhu, Z.; Xu, J. Small Molecules as Inhibitors of PCSK9: Current Status and Future Challenges. Eur. J. Med. Chem. 2019, 162, 212-233.

15. Disney, M. D. Inhibiting Translation One Protein at a Time. Trends Biochem. Sci. 2017, 42, 412-413.

16. Londregan, A. T.; Aspnes, G.; Limberakis, C.; Loria, P. M.; McClure, K. F.; Petersen, D. N.; Raymer, B.; Ruggeri, R. B.; Wei, L.; Xiao, J.; Piotrowski, D. W. Discovery of N-(piperidin-3-yl)-N-(pyridin-2yl)piperidine/piperazine-1-carboxamides as Small Molecule Inhibitors of PCSK9. Bioorg. Med. Chem. Lett. 2018, 28, 3685-3688.

17. Salmaso, V.; Sturlese, M.; Cuzzolin, A.; Moro, S. Exploring Protein-Peptide Recognition Pathways Using a Supervised Molecular Dynamics Approach. Structure 2017, 25, 655-662.e2.

18. Cuzzolin, A.; Sturlese, M.; Deganutti, G.; Salmaso, V.; Sabbadin, D.; Ciancetta, A.; Moro, S. Deciphering the Complexity of Ligand-Protein Recognition Pathways Using Supervised Molecular Dynamics (SuMD) Simulations. J. Chem. Inf. Mod. 2016, 56, 687-705.

19. Ciancetta, A.; Sabbadin, D.; Federico, S.; Spalluto, G.; Moro, S. Advances in Computational Techniques to Study GPCR-Ligand Recognition. Trends Pharmacol. Sci. 2015, 36, 878-890.

20. Sabbadin, D.; Moro, S. Supervised Molecular Dynamics (SuMD) as a Helpful Tool to Depict GPCRLigand Recognition Pathway in a Nanosecond Time Scale. J. Chem. Inf. Mod. 2014, 54, 372-376.

21. Lammi, C.; Zanoni, C.; Aiello, G.; Arnoldi, A.; Grazioso, G. Lupin Peptides Modulate the Protein-Protein Interaction of PCSK9 with the Low Density Lipoprotein Receptor in HepG2 Cells. Sci. Rep. 2016, 6, 29931.

22. Shao, J.; Tanner, S. W.; Thompson, N.; Cheatham, T. E. Clustering Molecular Dynamics Trajectories: 1. Characterizing the Performance of Different Clustering Algorithms. J. Chem. Theory Comput. 2007, 3, $2312-2334$.

23. Lammi, C.; Zanoni, C.; Arnoldi, A. A simple and High-throughput in-cell Western Assay Using HepG2 Cell Line for Investigating the Potential Hypocholesterolemic Effects of Food Components and Nutraceutics. Food Chem. 2015, 169, 59-64.

24. Zhang, Y.; Eigenbrot, C.; Zhou, L.; Shia, S.; Li, W.; Quan, C.; Tom, J.; Moran, P.; Di Lello, P.; Skelton, N. J.; Kong-Beltran, M.; Peterson, A.; Kirchhofer, D. Identification of a Small Peptide that Inhibits PCSK9 Protein Binding to the Low Density Lipoprotein Receptor. J. Biol. Chem. 2014, 289, 942-955.

25. Grazioso, G.; Bollati, C.; Sgrignani, J.; Arnoldi, A.; Lammi, C. The First Food-Derived Peptide Inhibitor of the Protein-Protein Interaction between Gain-Of-Function PCSK9 ${ }^{\mathrm{D} 374 \mathrm{Y}}$ and the LDL Receptor. J. Agric. Food Chem. 2018, 66, 10552-10557.

26. Lammi, C.; Sgrignani, J.; Roda, G.; Arnoldi, A.; Grazioso, G. Inhibition of PCSK9D374Y/LDLR ProteinProtein Interaction by Computationally Designed T9 Lupin Peptide. ACS Med. Chem. Lett. 2019, 10, 425-430.

27. Cornell, W. D.; Cieplak, P.; Bayly, C. I.; Kollman, P. A. Application of RESP charges to Calculate Conformational Energies, Hydrogen Bond Energies, and Free Energies of Solvation. J. Am. Chem. Soc. 1993, 115, 9620-9631. 
28. Maier, J. A.; Martinez, C.; Kasavajhala, K.; Wickstrom, L.; Hauser, K. E.; Simmerling, C. ff14SB: Improving the Accuracy of Protein Side Chain and Backbone Parameters from ff99SB. J. Chem. Theory Comput. 2015, 11, 3696-3713.

29. Wang, J.; Wolf, R. M.; Caldwell, J. W.; Kollman, P. A.; Case, D. A. Development and Testing of a General Amber Force Field. J. Comput. Chem. 2004, 25, 1157-1174.

30. McNutt, M. C.; Kwon, H. J.; Chen, C.; Chen, J. R.; Horton, J. D.; Lagace, T. A. Antagonism of Secreted PCSK9 Increases Low Density Lipoprotein Receptor Expression in HepG2 Cells. J. Biol. Chem. 2009, 284, 1056110570.

31. Harvey, M. J.; Giupponi, G.; Fabritiis, G. D. ACEMD: Accelerating Biomolecular Dynamics in the Microsecond Time Scale. J. Chem. Theory Comput. 2009, 5, 1632-1639.

32. Case, D. A.; Cerutti, D. S.; T.E. Cheatham, I.; Darden, T. A.; Duke, R. E.; Giese, T. J.; Gohlke, H.; Goetz, A. W.; Greene, D.; Homeyer, N.; Izadi, S.; Kovalenko, A.; Lee, T. S.; LeGrand, S.; P. Li, C. L.; Liu, J.; Luchko, T.; Luo, R.; Mermelstein, D.; Merz, K. M.; Monard, G.; Nguyen, H.; Omelyan, I.; Onufriev, A.; Pan, F.; Qi, R.; Roe, D. R.; Roitberg, A.; Sagui, C.; Simmerling, C. L.; Botello-Smith, W. M.; Swails, J.; Walker, R. C.; Wang, J.; Wolf, R. M.; Wu, X.; Xiao, L.; York, D. M.; Kollman, P. A. AMBER 2017; University of California: San Francisco, 2017.

33. Humphrey, W.; Dalke, A.; Schulten, K. VMD: Visual Molecular Dynamics. J. Mol. Graph. 1996, 14, 3338.

34. Roe, D. R.; Cheatham, T. E., 3rd. PTRAJ and CPPTRAJ: Software for Processing and Analysis of Molecular Dynamics Trajectory Data. J. Chem. Theory Comput. 2013, 9, 3084-3095.

35. Miller, B. R., 3rd; McGee, T. D., Jr.; Swails, J. M.; Homeyer, N.; Gohlke, H.; Roitberg, A. E. MMPBSA.py: An Efficient Program for End-State Free Energy Calculations. J. Chem. Theory Comput. 2012, 8, 3314-3321.

36. Gardner, R. A.; Ghobrial, G.; Naser, S. A.; Phanstiel, O. t. Synthesis and Biological Evaluation of New Acinetoferrin Homologues for Use as Iron Transport Probes in Mycobacteria. J. Med. Chem. 2004, 47, 4933-4940. 
Table of Contents Graphic

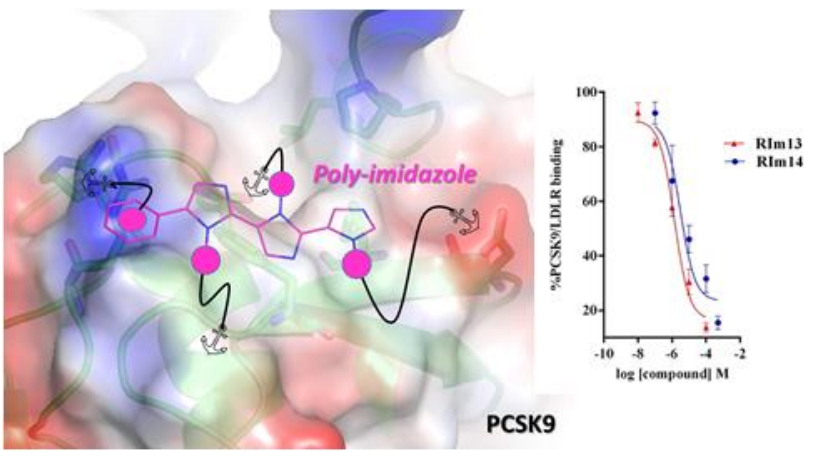

